San Jose State University

SJSU ScholarWorks

Master's Theses

Master's Theses and Graduate Research

Spring 2011

\title{
Carbon Electrodes with Tunable Surface Characteristics for Supercapacitors
}

Ramey Mohamed Abdelrahaman

San Jose State University

Follow this and additional works at: https://scholarworks.sjsu.edu/etd_theses

\section{Recommended Citation}

Abdelrahaman, Ramey Mohamed, "Carbon Electrodes with Tunable Surface Characteristics for Supercapacitors" (2011). Master's Theses. 3908.

DOI: https://doi.org/10.31979/etd.wuvb-as7a

https://scholarworks.sjsu.edu/etd_theses/3908

This Thesis is brought to you for free and open access by the Master's Theses and Graduate Research at SJSU ScholarWorks. It has been accepted for inclusion in Master's Theses by an authorized administrator of SJSU ScholarWorks. For more information, please contact scholarworks@sjsu.edu. 


\title{
CARBON ELECTRODES WITH TUNABLE SURFACE CHARACTERISTICS FOR SUPERCAPACITORS
}

\author{
A Thesis \\ Presented to \\ The Faculty of the Department of Chemical and Materials Engineering \\ San José State University
}

\author{
In Partial Fulfillment \\ of the Requirements for the Degree \\ Master of Science
}

by

Ramey M. Abdelrahaman

May 2011 
(C) 2011

Ramey M. Abdelrahaman

ALL RIGHTS RESERVED 
The Designated Thesis Committee Approves the Thesis Titled

\title{
CARBON ELECTRODES WITH TUNABLE SURFACE CHARACTERISTICS FOR SUPERCAPACITORS
}

\author{
by \\ Ramey M. Abdelrahaman \\ APPROVED FOR THE DEPARTMENT OF CHEMICAL AND MATERIALS \\ ENGINEERING \\ SAN JOSÉ STATE UNIVERSITY
}

May 2011
Dr. Melanie McNeil Department of Chemical and Material Engineering
Dr. Stacy Gleixner Department of Chemical and Material Engineering
Dr. Ho-Cheol Kim IBM Almaden Research Center




\title{
ABSTRACT \\ CARBON ELECTRODES WITH TUNABLE SURFACE CHARACTERISTICS FOR SUPERCAPACITORS
}

\author{
by Ramey M. Abdelrahaman
}

Experiments were conducted to determine the affects of surface texturization on the electrical properties of glassy carbon-based electrodes. Glassy carbon was etched using a block copolymer etch mask to introduce an ordered porous structure. Hybridized etched glassy carbon electrodes were developed to enhance electrical properties. Electrodes were hybridized using titania $\left(\mathrm{TiO}_{2}\right)$ and cupric oxide $\left(\mathrm{Cu}_{2} \mathrm{O}\right)$. Physical properties of glassy carbon electrodes were investigated using scanning electron microscopy (SEM), atomic force microscopy (AFM), and transmission electron microscopy (TEM). The electrical properties were investigated using cyclic voltammetry (CV). The experimental setup included $1 \mathrm{M}$ potassium hydroxide $(\mathrm{KOH})$, platinum foil as the counter electrode, and silver/silver chloride $(\mathrm{Ag} / \mathrm{AgCl})$ as the reference electrode. The fabricated electrodes were used as the working electrodes for CV measurements. Electrochemical results indicated an increase in capacitance for etched glassy carbon electrodes, TiO2-hybridized etched glassy carbon electrodes, and $\mathrm{Cu}_{2} \mathrm{O}$-hybridized etched glassy carbon electrodes compared to the control glassy carbon electrode.

Electrospun fibers were investigated as a high surface area carbon material. Electrospun fibers were deposited on aluminum substrates and investigated using SEM. 


\section{ACKNOWLEDGEMENTS}

Thanks go to Dr. Melanie McNeil and Dr. Ho-Cheol Kim for all of your time and effort to guide me on my way through the research process and writing process. I could not have done this without your help and guidance.

Thanks go to Dr. Stacy Gleixner for her input and direction during the course of my time here at San José State University. Thanks also go to Dr. John Bass for your assistance with CV measurements and equipment. To Dr. Jane Frommer, thank you for taking the time to train me on the AFM. Thanks also go to Blake Davis for your assistance and training with SEM. I would also like to thank IBM Almaden Research Center and the researchers for giving me the opportunity to work at a world-class research facility. The experiences I obtained will no doubt prove to be invaluable wherever I end up. 


\section{TABLE OF CONTENTS}

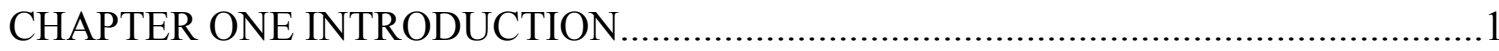

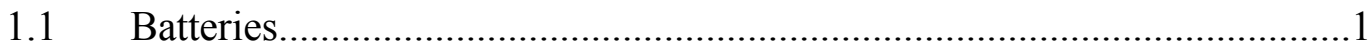

$1.2 \quad$ Electrochemical Capacitors......................................................................

$1.3 \quad$ Significance...................................................................................

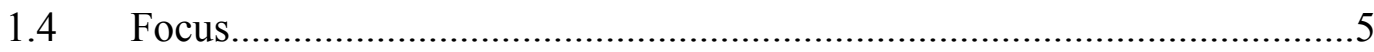

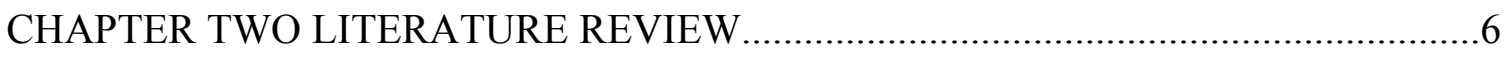

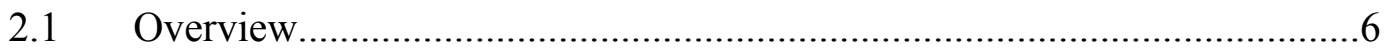

2.2 Asymmetric Supercapacitor...............................................................6

2.3 Carbon Electrode Material................................................................

$2.4 \quad$ Affects of Pore Size..............................................................................

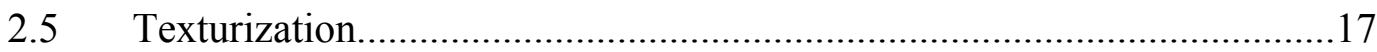

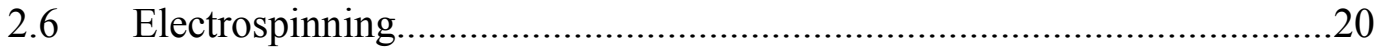

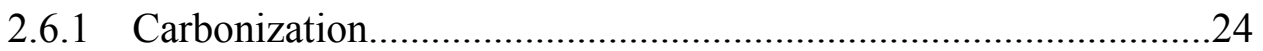

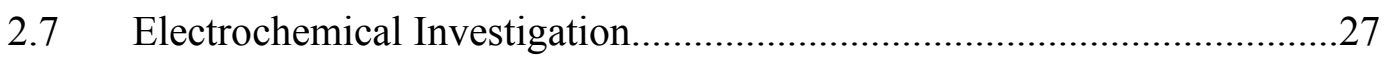

2.8 Surface Characterization.......................................................................30

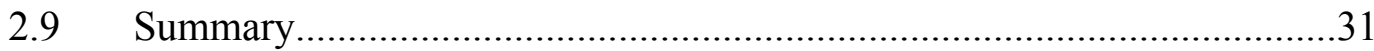

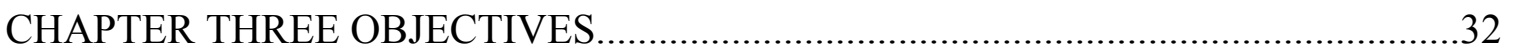

CHAPTER FOUR MATERIALS AND METHODS......................................................33

4.1 Introduction to Materials and Methods.......................................................33

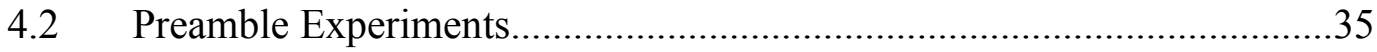




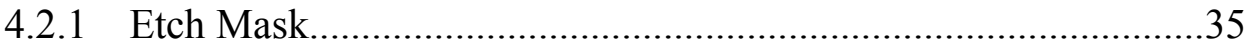

4.2.2 Electrospun Fibers......................................................................

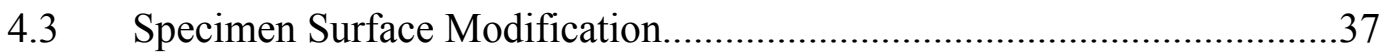

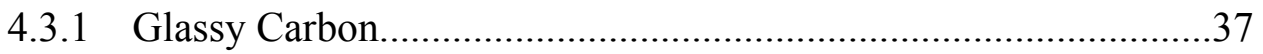

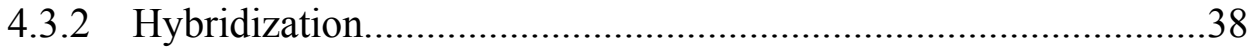

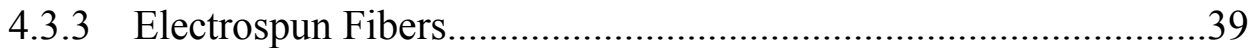

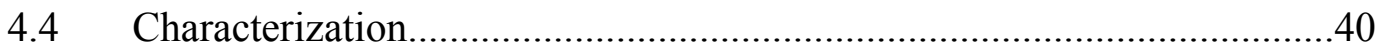

4.4.1 Surface..............................................................................

4.4.2 Electrochemical Characterization...................................................40

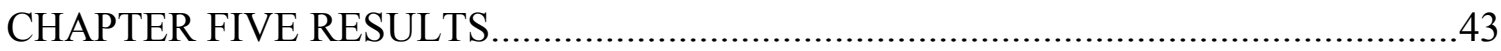

5.1 Surface Analysis of Carbon Electrodes......................................................45

5.2 Electrospun Carbon Fiber Electrodes.........................................................51

5.3 Electrochemical Results of Carbon Electrodes............................................52

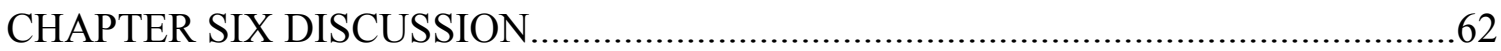

6.1 Analysis of Physical Characteristics of Etched Glassy Carbon..................62

6.2 Electrochemical Analysis.....................................................................63

6.3 Physical Characteristics Analysis of Electrospun Fibers...........................65

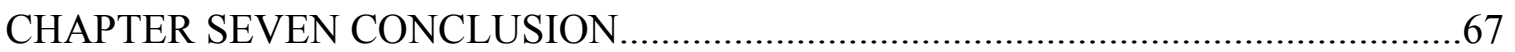

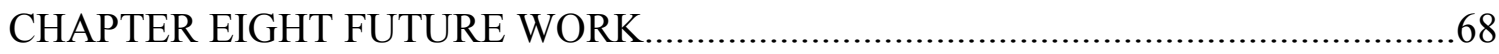

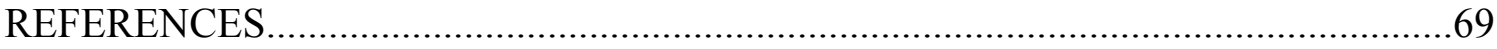

vii 


\section{LIST OF FIGURES}

Figure 1. Illustration of basic battery setup including: anode, cathode and electrolyte

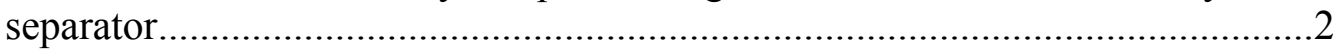

Figure 2. Power output of various energy sources versus the specific energy that can be stored.

Figure 3. Charge storage mechanism of a supercapacitor involving EDL.......................4

Figure 4. Electrochemical information from cyclic voltammetry .............................11

Figure 5. Normalized capacitance of carbon-based electrodes versus pore diameter......12

Figure 6. CV plot of activated carbon at a sweep rate of $10 \mathrm{mV} / \mathrm{s}$, potential range between $-0.2 \mathrm{~V}$ to $0 \mathrm{~V}$, showing region of pure capacitance.

Figure 7. Theoretical diagrams of charge storage in pores. a) negatively charged mesopore with cations at the mesopore wall forming double cylindrical capacitor. b) Negatively charged micropore surrounding cations forming a wire-in cylinder capacitor.

Figure 8. Normalized capacitance versus pore size of TiC-CDC electrodes .16

Figure 9. (Left) Theoretical phase diagram of linear block copolymers.

(Right) Experimental phase diagram of poly(styrene-block-isoprene).

Figure 10. Images made using SFM of PS-b-PEO thin film after spin coating in a) air, b) toluene, c) toluene + water vapor, d) water vapor, scan areas are $1 \mu \mathrm{m}$ by1 $\mu \mathrm{m}$.

Figure 11. (Left) Schematic of how the block copolymer template acts as a etch mask. (Right) Cross sectional SEM image of nanopores etched on a polymer substrate using block copolymer as a template.

Figure 12. Basic Setup of Electrospinning

Figure 13. A modification of an electrospinning setup to make hollow fibers using two solutions.

Figure 14. Porous polylactide in dichloromethane fibers investigated by SEM.... .23

viii 
Figure 15. Thermal gravimetric data of phenolic based carbon in an atmosphere of nitrogen.

Figure 16. Thermal gravimetric data of carbonization of phenolic based carbon in an atmosphere of nitrogen and air.

Figure 17. Increase in current density of electrodes results in a change of potential slope.

Figure 18. Impedance spectroscopy of 20 electrode capacitor showing exponential relationship as frequency was reduced.

Figure 19. Schematic of steps used to expose internal pores of glassy carbon electrodes

Figure 20. Experimental setup used for cyclic voltammetric measurements.

Equipment pictured included: Teflon electrode holder, glassy carbon working electrode, platinum counter electrode, and silver/silver chloride $(\mathrm{Ag} / \mathrm{AgCl})$ reference electrode.

Figure 21. Etch mask-coated glassy carbon electrode, obtained by AFM

Figure 22. Surface characteristics of etched glassy carbon electrodes with etch mass removed, obtained by AFM.

Figure 23. Surface characteristics of etched glassy carbon electrodes, with etch mask removed, obtained with SEM

Figure 24. Cross sectional TEM micrograph of pores in etched glassy carbon electrodes

Figure 25. Electrospun polymer fibers on aluminum foil, investigated with SEM..........52

Figure 26. Cyclic voltammetric plot showing 10 cycles of unetched glassy carbon electrodes.

Figure 27. Cyclic voltammetric plot of etched glassy carbon electrodes over 10 cycles

Figure 28. Cyclic voltammetric plot of $\mathrm{TiO}_{2}$-hybridized etched glassy carbon electrodes, showing degradation of capacitance over 10 cycles. 
Figure 29. Cyclic voltammetric plot of a $\mathrm{Cu}_{2} \mathrm{O}$-hybridized etched glassy carbon electrode, showing degradation of capacitance over 10 cycles.......................57

Figure 30. Cyclic voltammetric plots of unetched glassy carbon electrode, etched glassy carbon electrode, $\mathrm{TiO}_{2}$-hybridized etched glassy carbon electrodes, and $\mathrm{Cu}_{2} \mathrm{O}$-hybridized etched glassy carbon..................................................58

Figure 31. Capacitance as a function of cycling showing power law degradation of

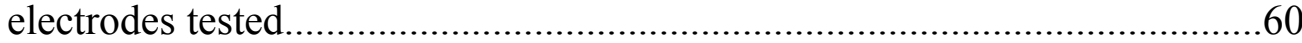

Figure 32. Cyclic voltammetric plot of a gold electrode coated with $\mathrm{CuO}$ nanobelts......65 


\section{LIST OF TABLES}

Table 1. Capacitance values of commonly used activated carbon..................................11

Table 2. Fiber characteristics after carbonization of nanoparticle glassy carbon............24

Table 3. Experimental matrix used to texturize glassy carbon electrode material...........33

Table 4. Capacitance values for electrodes tested......................................................59 


\section{CHAPTER ONE \\ INTRODUCTION}

The main source of energy used today to generate electricity and to power vehicles comes from fossil fuels. Researchers are currently studying energy production methods using renewable resources. However, the disadvantage of this type of energy production is availability. The limited availability of renewable resources keeps fossil fuels as the number one energy source. A way to overcome this obstacle is to store the energy produced from renewable sources with batteries or electrochemical capacitors.

\section{$1.1 \quad$ Batteries}

Devices that store energy in a chemical form are called batteries. Batteries consist of anodes, cathodes, electrolytes, and porous electrolyte separators. Interactions between the electrolyte and the electrodes produce a net flow of electrons, as shown in Figure 1 [2]. Electrochemical reactions occur at the electrode/electrolyte interface.

Batteries use a mixture of conduction modes: ionic and electronic. The ionic conduction mode involves the movement of ions from the electrolyte to the electrodes. Electronic conduction is the movement of electrons through the electrodes. The voltage densities of batteries are dependent on the ability of the conduction modes to operate. Conduction modes are affected by the chemical reactions between the electrodes and the electrolyte. Figure 2 shows a comparison between voltage densities versus mass of the electrical storage devices. Lead acid batteries are at the bottom of the plot, with the lowest voltage density to mass ratio. Lithium batteries are at the top with the highest current density and the lowest mass. 


\section{Battery}

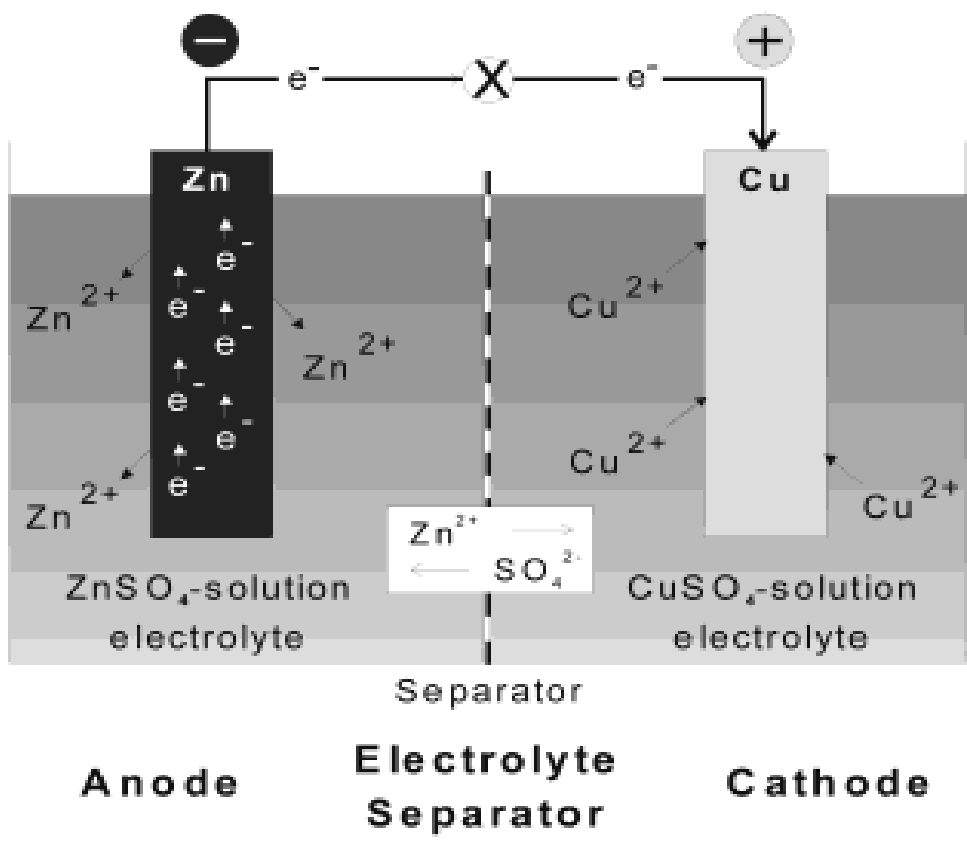

Figure 1. Illustration of basic battery setup including: anode, cathode and electrolyte separator (Reprinted with permission from M. Winter and R.J. Brodd, Copyright 2004, Chemical Review.)

Limitations of batteries are low power and poor charge/discharge cycle ability. Power is related to how rapidly energy can be stored and released. The mechanisms of releasing stored energy in batteries are dependent on the reaction rates between the electrolyte and electrodes. Poor cycle ability of batteries is due to the inability of ions to attach and release from the reactive species repeatedly. After each cycle, some ions fail to break away from the reactive components. As a result, a low concentration of ions remain flowing in the system, which reduces the ability to store charge. An electrical storage device that uses an electric field to store charge is called a capacitor. Capacitors store charge on the surface of electrodes instead of in a chemical reaction. Capacitors 
have higher power than batteries because charge is discharged directly rather than through chemical reactions. According to Winter et al., capacitors have power comparable to combustion engines. A representation of power as a function of specific energy for various devices is shown in Figure 2 [2]. Another type of capacitor is an electrochemical capacitor. This device takes advantage of storing charge on the surface of electrodes and in the electrolyte.

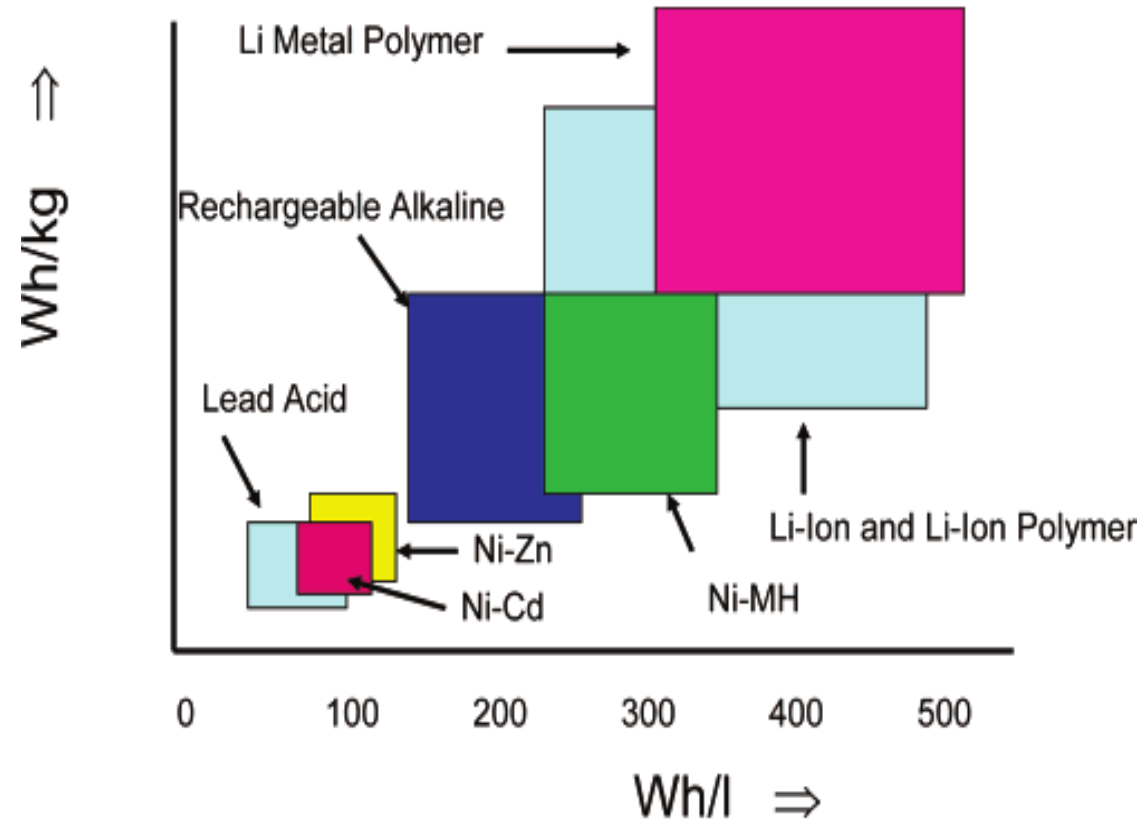

Figure 2. Power output of various energy sources versus the specific energy that can be stored (Reprinted with permission from M. Winter and R.J. Brodd, Copyright 2004, Chemical Review.)

\subsection{Electrochemical Capacitors}

Electrochemical capacitors are similar to batteries. The are known as supercapacitors and they contain anodes, cathodes, and an electrolyte. Electrochemical capacitors take advantage of storing charge in both the electrolyte and on the electrode 
surface. The electrolyte/electrode interface stores charge in an electrical double layer (EDL). The EDL occurs as a result of the interactions between the electrolyte and the electrodes' surfaces. Positive and negative charges align in sequence with their respective charges to form the EDL. When discharge occurs, electrons rearrange back to equilibrium causing a shift in the EDL. The rearranging of positive and negative charges causes a net flow from the negative to the positive electrodes. Figure 3 illustrates the EDL on the surface of electrodes in a supercapacitor [2].

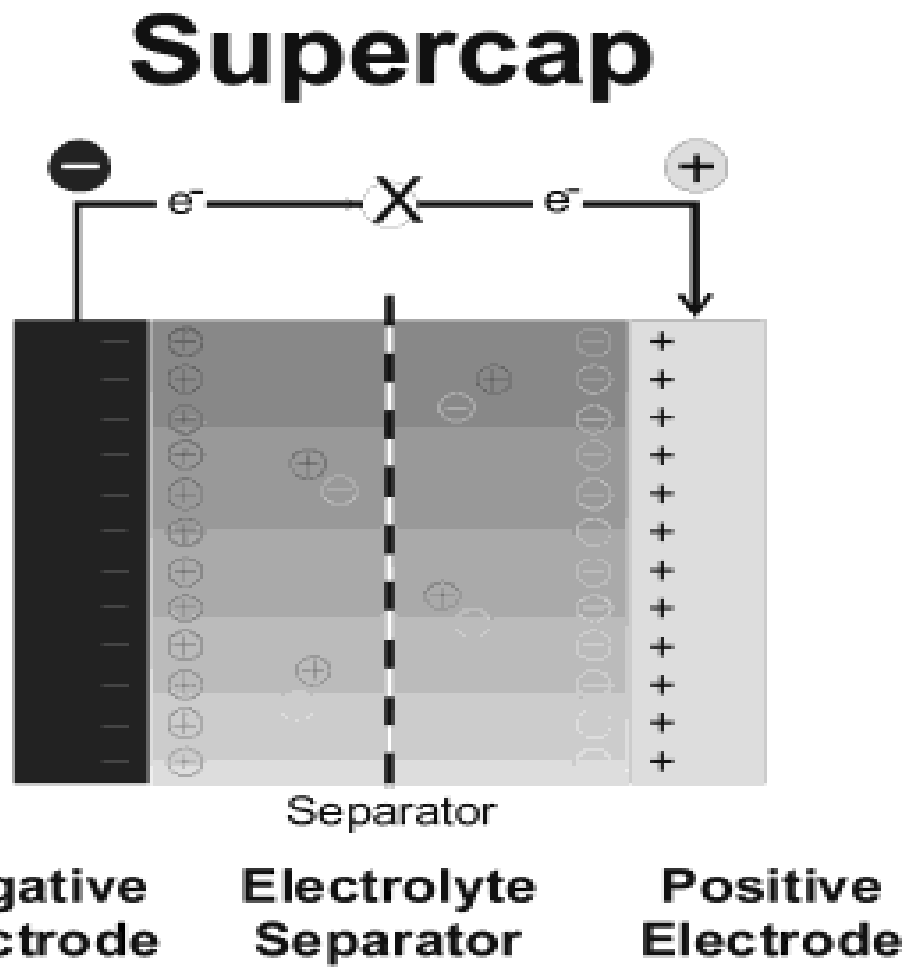

Figure 3. Charge storage mechanism of a supercapacitor involving EDL (Reprinted with permission from M. Winter and R.J. Brodd, Copyright 2004, Chemical Review.) 


\subsection{Significance}

Improvements of electrical storage devices are needed before renewable energy production can replace fossil fuels. Electrical storage in batteries and electrochemical capacitors occur on the surface of electrodes. Increasing the rates of reaction and surface area of electrodes may potentially increase the stored charge and power of these devices. Exposing more surface by scratching or etching will increase the surface area. An example where modification of a material's surface will benefit its electrical properties is glassy carbon. Glassy carbon electrodes have a smooth surface with a porous internal structure. To increase the surface area of glassy carbon electrodes, the glassy surface will be removed to expose pores. With more surface area to interact with the electrolyte, more charge can be stored.

The charge density can be increase by introducing electrochemical reactions to the electrodes. This can be done by hybridizing electrodes with the addition of catalysts to the surface. The hybridization would incorporate the electrical properties of both the electrode and hybridizing material. This will lead to faster ion and electron conductions as well as adding surface area to increase capacitance.

\subsection{Focus}

This study focused on making glassy carbon electrodes with increased surface area to increase capacitance. Hybridization of glassy carbon will be done to increase surface area and to introduce an electrochemical component. Some considerations will be made to fabricate electrodes that are not harmful to produce, inexpensive, and are tunable for the desired charge/discharge rates and storage densities. 


\section{CHAPTER TWO \\ LITERATURE REVIEW}

\subsection{Overview}

Supercapacitors have been studied by many researchers because of their electrical properties, such as high energy and power densities. To improve these devices, an understanding of charge storage mechanisms is necessary. This chapter discusses the development of electrodes with improved electrical characteristics compared to other electrodes currently in use. Carbon as an electrode material is the focus.

Processing methods of carbon are considered for the development of electrodes. One type of process involves self-assembly block copolymers as an etching template for glassy carbon. The template is used to expose its internal porous structure in an ordered fashion. Another method of increasing surface area involves fabricating carbon electrodes from thin polymer fibers. Forming polymer fibers with high surface area using electrospinning is investigated.

\subsection{Asymmetric Supercapacitors}

Pell and Conway investigated supercapacitors using electrodes with different but complimentary charge storage mechanisms. Supercapacitors that use different electrodes in the same device are called asymmetric supercapacitors [3]. Asymmetric supercapacitors use multiple electrodes with different electrical properties to take advantage of their characteristics. An example of this is to use a battery and capacitive electrodes in tandem. This combination provides charge storage using the electrolyte, 
electric double layer mechanisms of the capacitance electrode, and the electrochemical charge storage of the battery electrode [3].

According to the authors Pell and Conway, the combination of both types of electrodes in a single device should provide high energy and power densities. The use of capacitor electrodes improve cycle ability compared to devices that use battery electrodes because the electrochemical reactions are not fully reversible [3]. Some ions move back and forth from the electrodes to the electrolyte and may not return to their original states. After numerous cycles, the chemical potential difference will not be sufficient to facilitate an electrochemical reaction. A theoretical baseline of the specific capacitance for porous carbon given by the authors was $400 \mathrm{~F} / \mathrm{g}$ at $1 \mathrm{~V}$ [3]. To obtain the benefits that come with an asymmetric supercapacitor, both electrodes need to have characteristics that complement each other.

\subsection{Carbon Electrode Material}

Dekanski et al. studied the electrical characteristics of surface modified glassy carbon. The modification was to increase surface area available for interaction between the electrolyte and electrode. In this study, the authors conducted experiments using various methods of surface modification. These methods included [4]:

- Polishing with emery paper

- Anodic polarization in $0.5 \mathrm{M}$ sulfuric acid $\left(\mathrm{H}_{2} \mathrm{SO}_{4}\right)$ at varying potentials for durations up to 1980 seconds

- Anodic polarization in $1 \mathrm{M}$ sodium hydroxide $(\mathrm{NaOH})$ at varying potentials for durations up to 720 seconds

- Cathodic polarization in $0.5 \mathrm{M} \mathrm{H}_{2} \mathrm{SO}_{4}$ at varying potentials for durations up to 635 seconds

Atomic electron spectroscopy (AES) and x-ray photoelectron spectroscopy (XPS) 
were used to examine the surface composition of the electrodes. This was needed to determine the interacting constituents of the supercapacitor. It was also necessary to determine if chemical changes of the electrolyte and electrodes occurred during the experiments. Cyclic voltammetry (CV) in an electrolyte of $0.5 \mathrm{M} \mathrm{H}_{2} \mathrm{SO}_{4}$ and $1 \mathrm{M} \mathrm{NaOH}$ was used to examine the affects of surface modification on the electrical characteristics of the glassy carbon electrodes.

The authors tested two samples to determine the affects of surface polarization on the electrical properties of carbon electrodes. Samples K and G were thermally annealed at $1000^{\circ} \mathrm{C}$ and $2500^{\circ} \mathrm{C}$, respectively. Results indicated sample $\mathrm{K}$ experienced an initially higher electric double layer (EDL) than sample G. However, with increasing polarization of the surface sample G began to experience a higher EDL than sample K. Results indicated that the use of different electrolytes used in CV measurements determined which samples had larger EDLs. Cyclic voltammetry scans in $0.5 \mathrm{M} \mathrm{H}_{2} \mathrm{SO}_{4}$ resulted in a larger EDL for sample G than sample K.

The authors examined surfaces of the electrodes and concluded that sample $G$ performed better in the $\mathrm{H}_{2} \mathrm{SO}_{4}$, because the sulfur anions encouraged oxidation of carbon to form a carbon oxide layer. The capacitance was limited by the ability of sulfur to move into the surface of the electrodes and react. Sample G had a more homogeneous structure that allowed the subsurface to be more accessible to the sulfur. Electrical characteristics of electrodes were affected by the electrolyte and surface modification done to the electrodes [4]. 
Frankowiak and Beguin studied the use of carbon as an electrode material because of its abundance, low cost, ease of process, resistance to corrosion, and wide range of working temperatures. As an electrode material, carbon exhibits an electric double layer naturally. Carbon is also known to store charge using capacitance and chemical reactions. However, these reactions are dependent on the manipulations done to the surface of carbon [5]. Carbon's EDL is dependent on the carbon/electrolyte interface. The thickness of the electric double layer is related to the ability for charges to be attracted to carbons surface and other electrons. The attraction of ions to carbon electrodes is a natural product of carbon's electrical properties [5]. The capacitance due to the EDL on carbon has values ranging from $15-50 \mu \mathrm{F} / \mathrm{cm}^{2}$. The ideal capacitance of carbon is $250 \mathrm{~F} / \mathrm{g}$, assuming an average EDL capacitance and surface area of $25 \mu \mathrm{F} / \mathrm{cm}^{2}$ and $1000 \mathrm{~m}^{2} / \mathrm{g}$, respectively. However, the actual capacitance is only on the order of tens of $\mathrm{F} / \mathrm{g}$. This is due to the limited ability of electrons to interact with the surface of carbon [5].

Capacitance can vary depending on the technique used to measure it. Common techniques for measuring capacitance, along with other electrical properties, are cyclic voltammetry, impedance spectroscopy, and galvanostatic charge/discharge. The ideal charge/discharge distribution of electrodes is shown in Figure 4. An instantaneous charge rebound when the potential sweep is in reverse indicates the capacitance region [5]. Capacitance values for common porous carbon electrodes are shown in Table 1 [5]. 


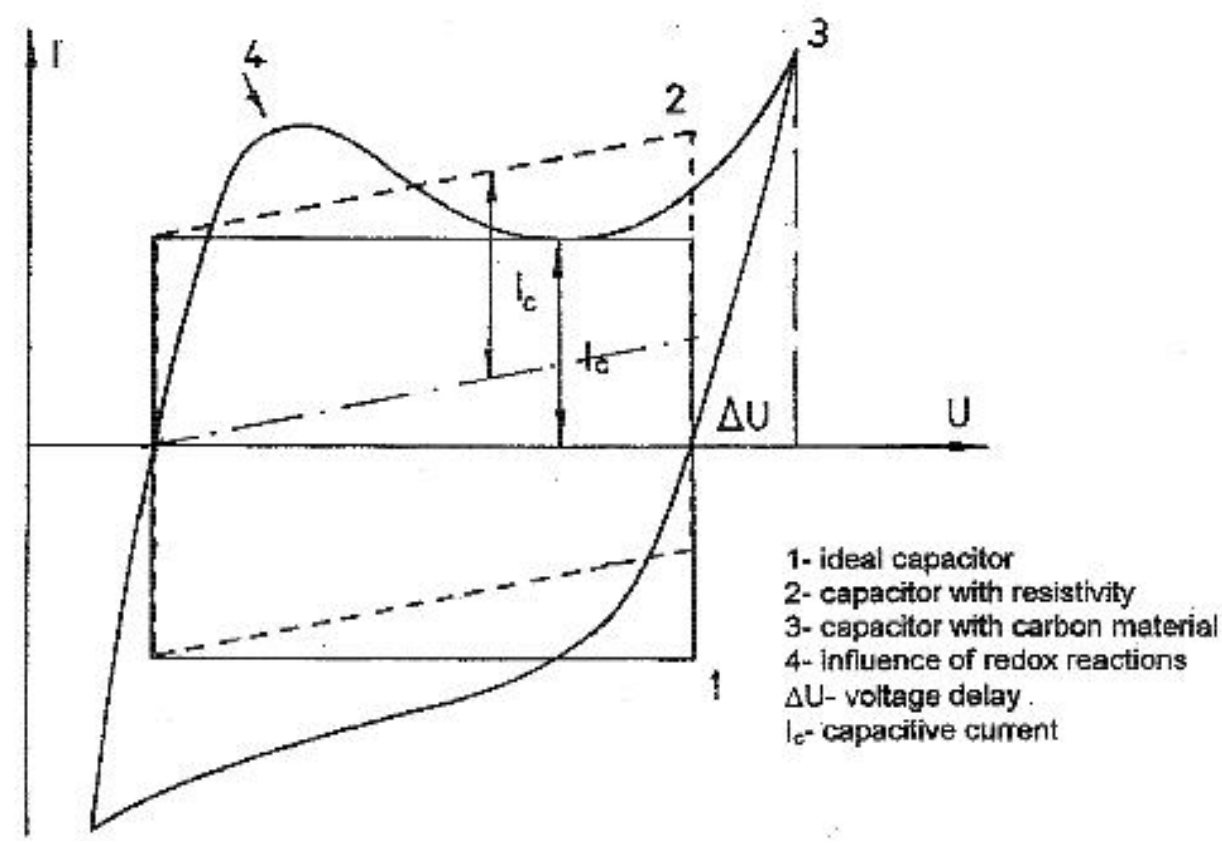

Figure 4. Electrochemical information from cyclic voltammetry (Reprinted with permission from E. Frankowiak and F. Beguin, Copyright 2001, Carbon.) 
Table 1. Capacitance values of commonly used activated carbon [5].

\begin{tabular}{|c|c|c|c|c|c|}
\hline Carbon & $\begin{array}{l}\text { Specific Capacity } \\
(\mathrm{F} / \mathrm{g})\end{array}$ & $\begin{array}{l}\text { Specific Capacity } \\
\left(\mathrm{F} / \mathrm{cm}^{2}\right)\end{array}$ & BET $\left(\mathrm{m}^{2} / \mathrm{g}\right)$ & $\begin{array}{l}\text { Pore Volume } \\
(\mathrm{cc} / \mathrm{g})\end{array}$ & $\begin{array}{l}\text { Pore Size } \\
(\AA)\end{array}$ \\
\hline $\mathrm{M}-10$ & 55.95 & 0.041 & 1370 & 0.500 & 9.12 \\
\hline $\mathrm{M}-14$ & 57.20 & 0.005 & 1223 & 0.561 & 9.60 \\
\hline $\mathrm{M}-15 \mathrm{~A}$ & 78.10 & 0.043 & 1800 & 0.629 & 9.17 \\
\hline $\mathrm{M}-15 \mathrm{~B}$ & 55.80 & 0.034 & 1624 & 0.563 & 9.37 \\
\hline $\mathrm{M}-15 \mathrm{C}$ & 63.34 & 0.042 & 1518 & 0.600 & 9.79 \\
\hline $\mathrm{M}-20$ & 100.00 & 0.046 & 2130 & 0.709 & 14.73 \\
\hline $\mathrm{M}-30$ & 62.90 & 0.024 & 2571 & 1.230 & 14.95 \\
\hline A-10 & 35.30 & 0.310 & 1150 & 0.424 & \\
\hline A-20 & 41.20 & 0.020 & 2012 & 0.902 & 14.23 \\
\hline SACF-20 & 48.80 & 0.027 & 1839 & 0.699 & 9.74 \\
\hline SACF-25 & 27.90 & 0.011 & 2371 & 0.977 & 11.93 \\
\hline
\end{tabular}

\section{$2.4 \quad$ Affects of Pore Size}

According to Frankowiak and Beguin, charge density was limited at the surface/electrolyte interaction in pore sizes smaller than $2 \mathrm{~nm}$ in diameter, because the diameter of ions are larger than $2 \mathrm{~nm}$. This leads to pores being unfilled by ions and surface area not utilized [5]. Understanding the limitations of pore sizes has pushed researchers to look for ways to utilize mesoporous carbon. Mesoporous carbon has pore sizes between $2 \mathrm{~nm}$ and $50 \mathrm{~nm}$ diameter.

According to Chmiola et al., if the pore diameters are smaller than $2 \mathrm{~nm}$, capacitance increases. The capacitance increases due to distortions of the ion, causing carbon to be closer to the ion's center [6]. The increased capacitance of carbon with smaller pore sizes is shown in Figure 6 [6]. In general, pores smaller than the ionic radius plus its outer shell results in decreased capacitance. According to the authors, 
there was a critical pore size where capacitance was at its maximum. However, the increased capacitance comes at a price of slower ion mobility, which reduces power [6]. Slow discharge has uses for applications requiring low power for long operation, such as a flashlight.

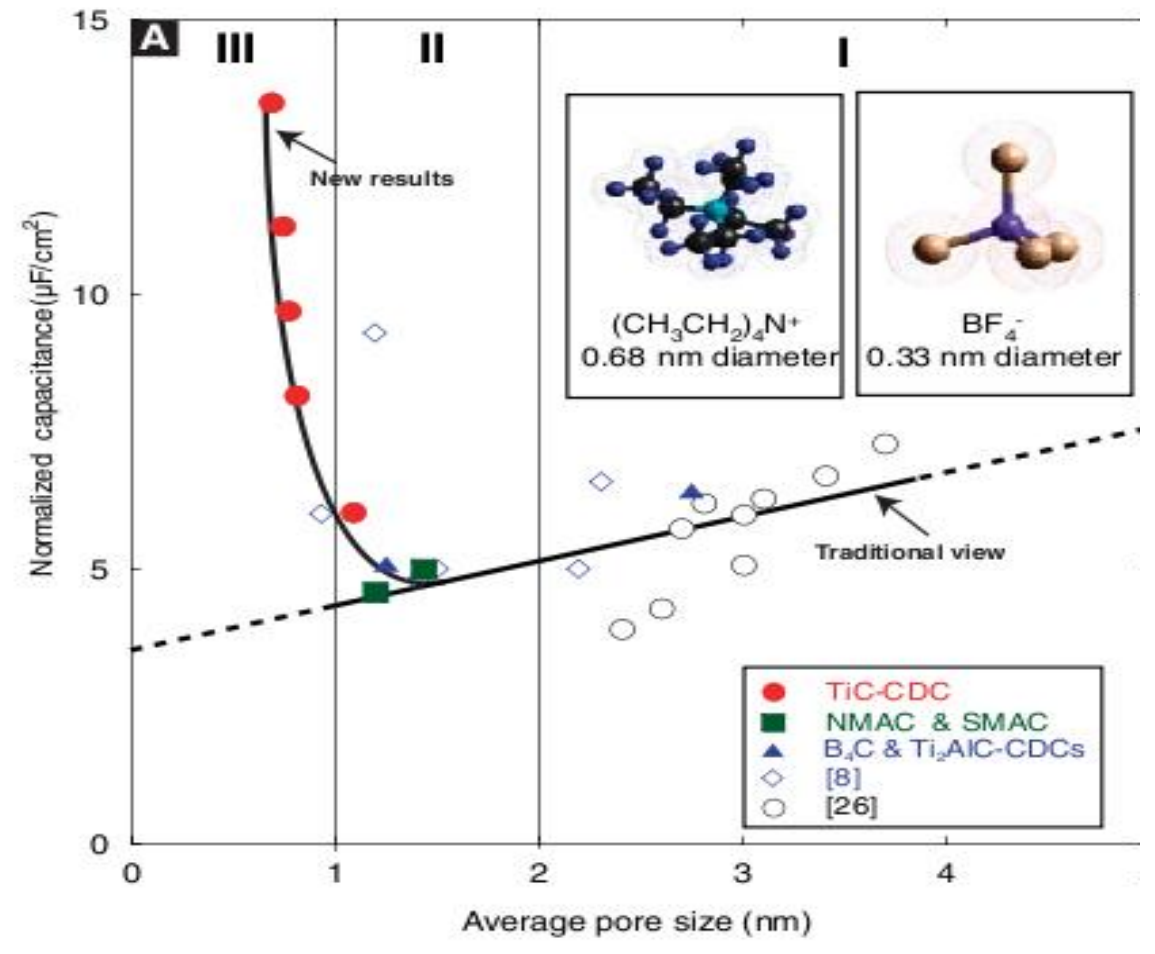

Figure 5. Normalized capacitance of carbon-based electrodes versus pore diameter (Reprinted with permission from J. Chmiola, G. Yushin, Y. Gogotsi, C. Portet, P, Simon and P.L. Taberna, Copyright 2006, Science.)

The availability of ions to transport into micropores was also investigated using micro-electrodes to investigate ion diffusion and charge characteristics in activated carbon particles by Malmberg et al. [7]. Ion transport properties in microporous particles and in particles with a combination of pore sizes including macro, meso, and micropores were studied. An electrolyte of $6 \mathrm{M}$ potassium hydroxide $(\mathrm{KOH})$ was used in their 
experimental setup. A preliminary potential sweep was conducted prior to running the experiment. A potential was applied to the carbon particles with a sweep rate of $1 \mathrm{mV} / \mathrm{s}$ from -0.4 to $0.2 \mathrm{~V}$ versus the reference electrode, followed by a potential sweep rate of $10 \mathrm{mV} / \mathrm{s}$ from -0.2 to $0 \mathrm{~V}$. The preliminary potential sweep fully immersed the carbon particles with electrolyte and formed an oxidation layer on the particles. The capacitance of the carbon particles was enhanced by the oxidation layer [7].

Next, cyclic voltammetry was performed, followed by a galvanostatic charge/discharge at the minimum current that allowed an adequate noise to signal ratio. Finally, impedance spectroscopy was used to investigate ion transportation in micropores [7]. Results showed carbon electrodes act purely capacitive under a potential range from $0 \mathrm{mV}$ to $-200 \mathrm{mV}$. As shown in Figure 7, no electrochemical peaks were present in the cyclic voltammetric plot of the electrodes tested by Malmberg et al. 


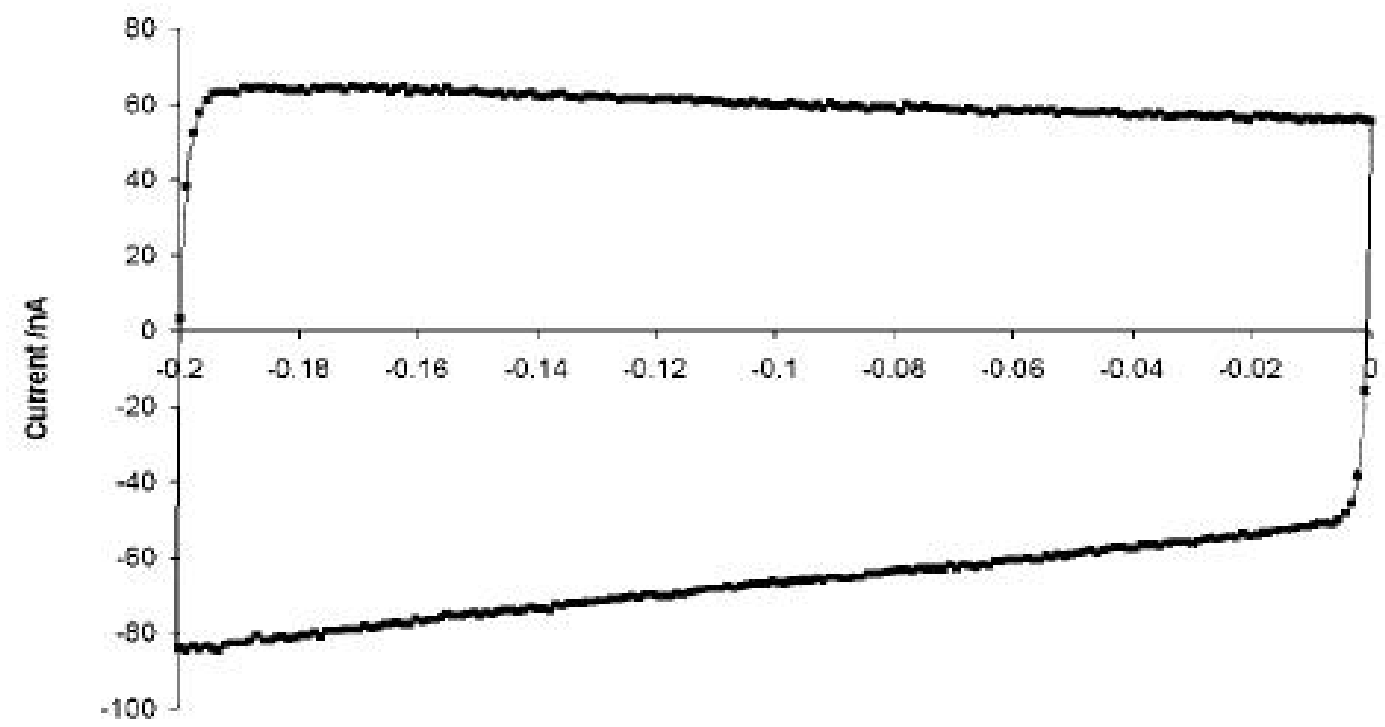

Potential $N$

Figure 6. CV plot of activated carbon at a sweep rate of $10 \mathrm{mV} / \mathrm{s}$, potential range between $-0.2 \mathrm{~V}$ to $0 \mathrm{~V}$, showing region of pure capacitance (Reprinted with permission from H. Malmberg, M. Zuleta, A. Lundblad and P. Bjornbom, Copyright 2006, J. Electrochem. Soc.)

According to Malmberg et al., impedance spectroscopy indicated ion transportation of potassium or hydroxyl ions from the electrolyte into the micropores. Having material with mesopores in tandem with micropores allowed ions access to micropores at much faster rates than in micropores alone. The gradual size constriction of the combined mesopores and micropores eased ion distortion.

Huang et al. have also studied some theoretical models on the affects of pores smaller than $1 \mathrm{~nm}$ in diameter. Their findings were in agreement with Chmiola et al. and Malmberg et al. Ion transport into pores smaller than the ions and their outer shells occurred [8]. According to Huang et al., models for micropores are insufficient due to various pore shapes. When considering micropores as a cylinder, the cations circle 
around the negative pore to make a wire-in cylinder capacitor. Comparing this to the double walled cylindrical capacitor that forms in mesopores shown in Figure 7, it is difficult to determine which model leads to higher charge densities [8].

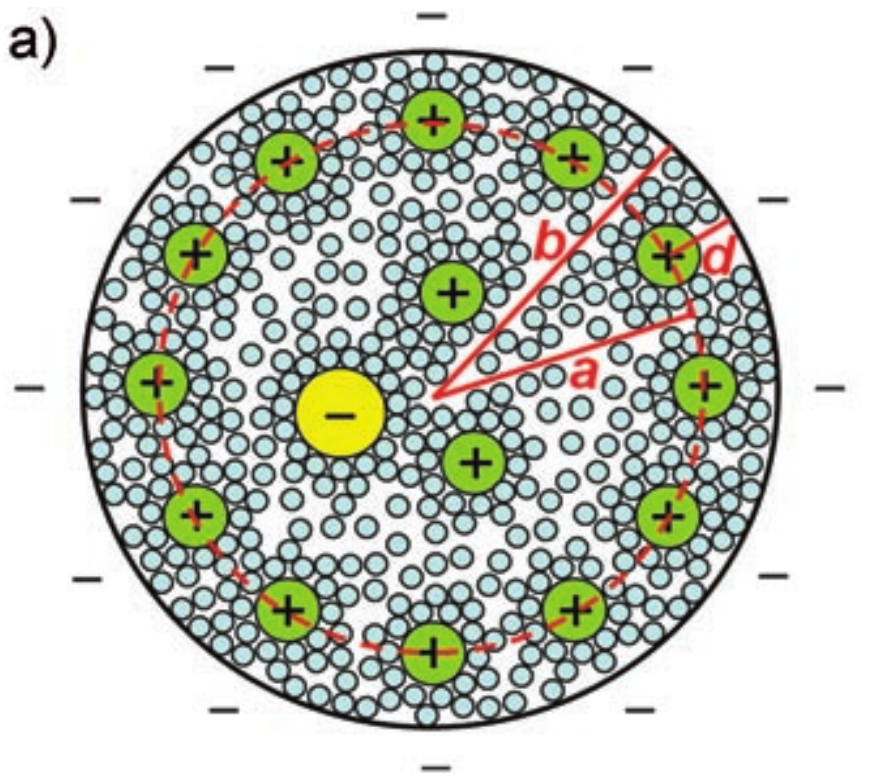

b)

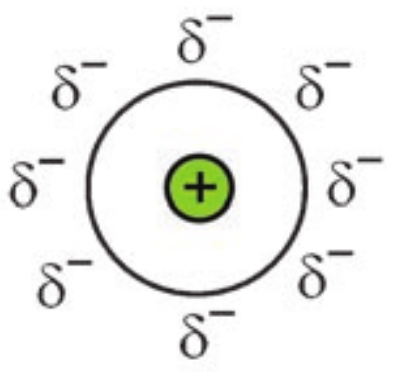

Figure 7. Theoretical diagrams of charge storage in pores. a) negatively charged mesopore with cations at the mesopore wall forming double cylindrical capacitor. $b$ ) Negatively charged micropore surrounding cations forming a wire-in cylinder capacitor (Reprinted with permission from J. Huang, B.J. Sumpter and V. Meunier, Copyright 2008, Angew. Chem. Int. Ed.)

Largeot et al. studied the relationship between ion size and pore size for EDL

capacitors. Pore structure was examined using the gas-absorption technique with argon and nitrogen at $77 \mathrm{~K}$, and carbon dioxide at $300 \mathrm{~K}$. Specimens tested were titanium carbide derived carbon electrodes, which have an average pore diameter in the range of 0.65 to $1.10 \mathrm{~nm}$. 
The electrochemical characterization was taken at $60^{\circ} \mathrm{C}$ using 1-ethyl-3-methyl imidazolium bis(trifluoromethanesulfonyl)imide ionic liquid. Bis(trifluoromethanesulfonyl)imide has ions with diameters of approximately $0.79 \mathrm{~nm}$. Ions of 1-ethyl-3methyl imidazolium has a diameter of approximately $0.76 \mathrm{~nm}$. A sweep rate of $20 \mathrm{mV} / \mathrm{s}$ was used in cyclic voltammetry (CV) measurements that produced current densities of 5$100 \mathrm{~mA} / \mathrm{cm}^{2}$. The potential ranges used in a two electrode cell were between $0 \mathrm{~V}$ and 3 V. No faradic affects were observed from CV measurements. Impedance spectroscopy showed titanium carbide derived carbon electrodes have an electric double layer capacitance behavior [9]. Maximum capacitance was observed when the pore diameter was approximately equivalent to the ion diameter, shown in Figure 8 [9].

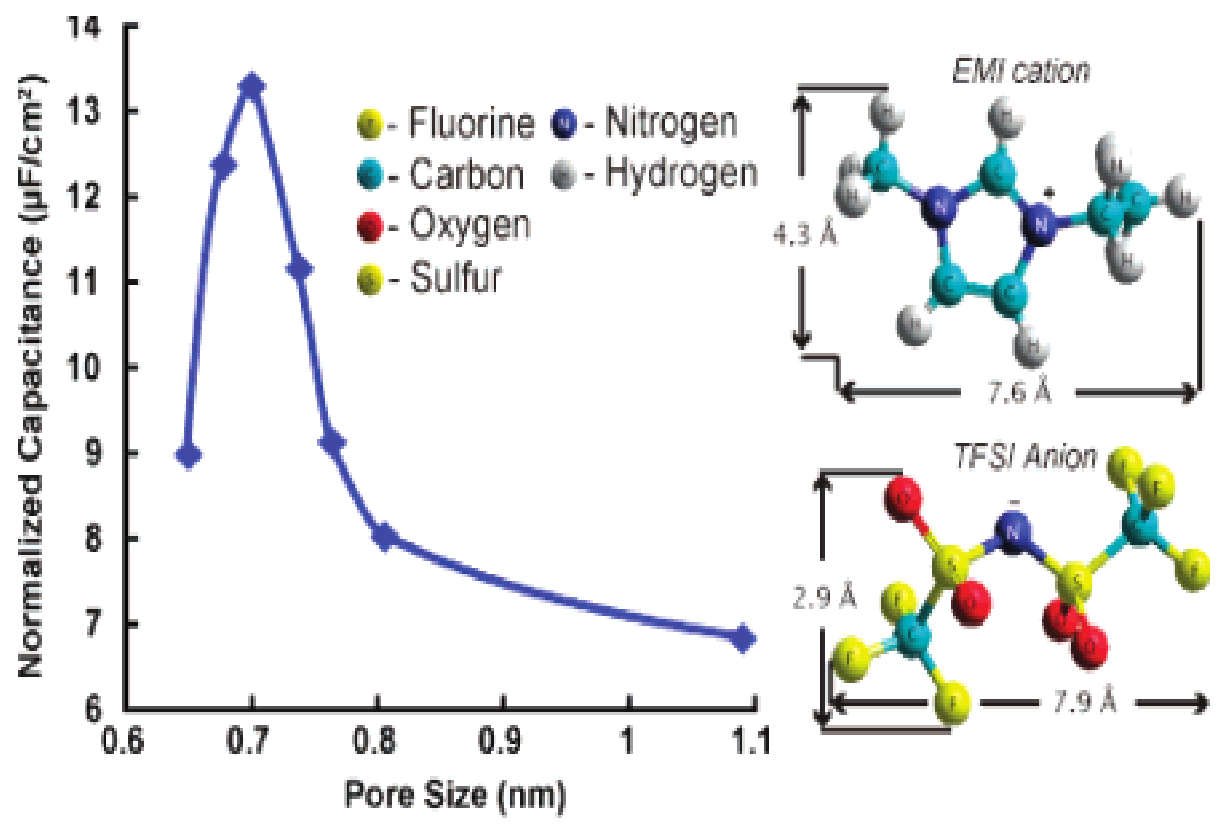

Figure 8. Normalized capacitance versus pore size of TiC-CDC electrodes (Reprinted with permission from C. Largeot, C. Portet, J. Chmiola, P.L. Taberna, Y. Gogotsi and P. Simon, Copyright 2008, J. Am. Chem. Soc.) 


\subsection{Texturization}

Kim et al. studied block copolymers and ways to tune their structures. According to the authors, block copolymers contain two polymers, polymer 1 and polymer 2, that are homogeneous on their own, but when combined become inhomogeneous. They form chains with one end comprised of polymer 1 and the other end polymer 2. Tuning was done by introducing different concentrations and molecular weights of polymers 1 and 2 to form domains. As shown in Figure 9, the affects between concentrations, molecular weights and energy balances between polymer chains result in repeatable domains [10].
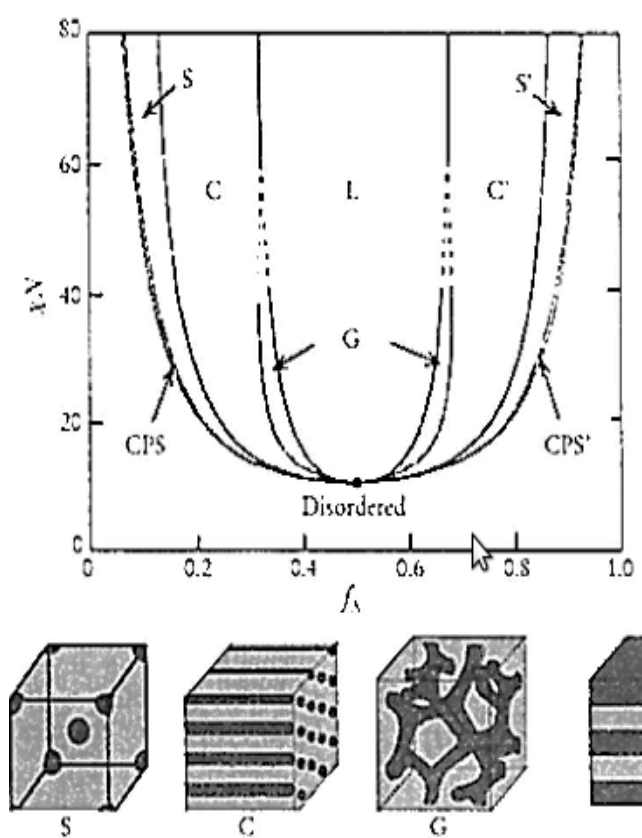

C.

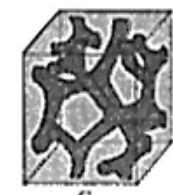

G

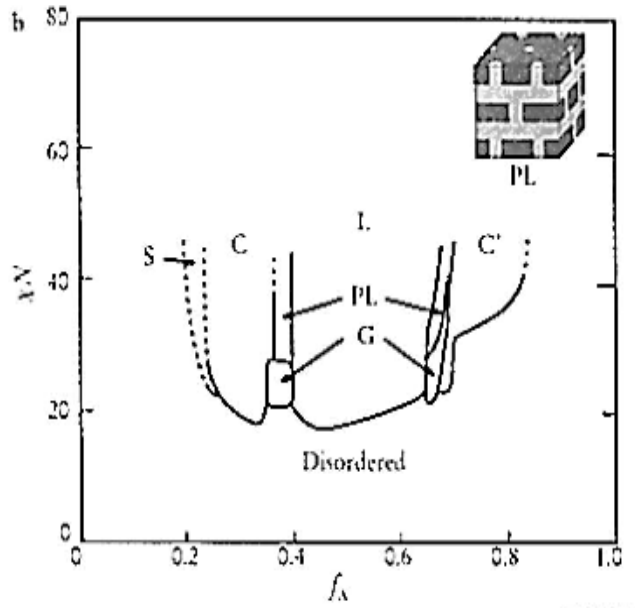

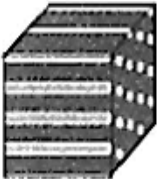

C'

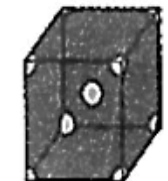

s'

Figure 9. (Left) Theoretical phase diagram of linear block copolymers. (Right) Experimental phase diagram of poly(styrene-block-isoprene) (Reprinted with permission from Bates, F. S.; Fredrickson, G. H., Physics Today, 52, 2, 1999, Copyright 1999, American Institute of Physics) 
Kim et al. studied the potential use of block copolymer thin films to pattern surfaces. The study involved controlling the atmosphere during spin-coating of block copolymers to form thin films with oriented cylindrical microdomains. The block copolymers tested were poly(styrene-block-(ethylene oxide)) (PS-b-PEO) in a toluene. Block copolymers were applied using spin coating on (100) silicon wafers. Spin coating was performed after 40 seconds using 3 separate vapor atmospheres: toluene vapor, water vapor, and toluene + water vapors [11].

The results under just toluene were poly(ethylene oxide) (PEO) domains parallel to the surface of the substrate. This occurred due to the high solubility of polystyrene (PS) in toluene compared to PEO in toluene. The results of using toluene plus water vapor gave a more vertical orientation of PEO. This was because PEO dissolves more readily in water than PS does in water. The evaporation of water vapor causes selfassembly of PEO to be in the direction of evaporation, which propagated through the film. The result of using only water vapor resulted in a vertical orientation of PEO domains as shown in Figure 10 [11]. 

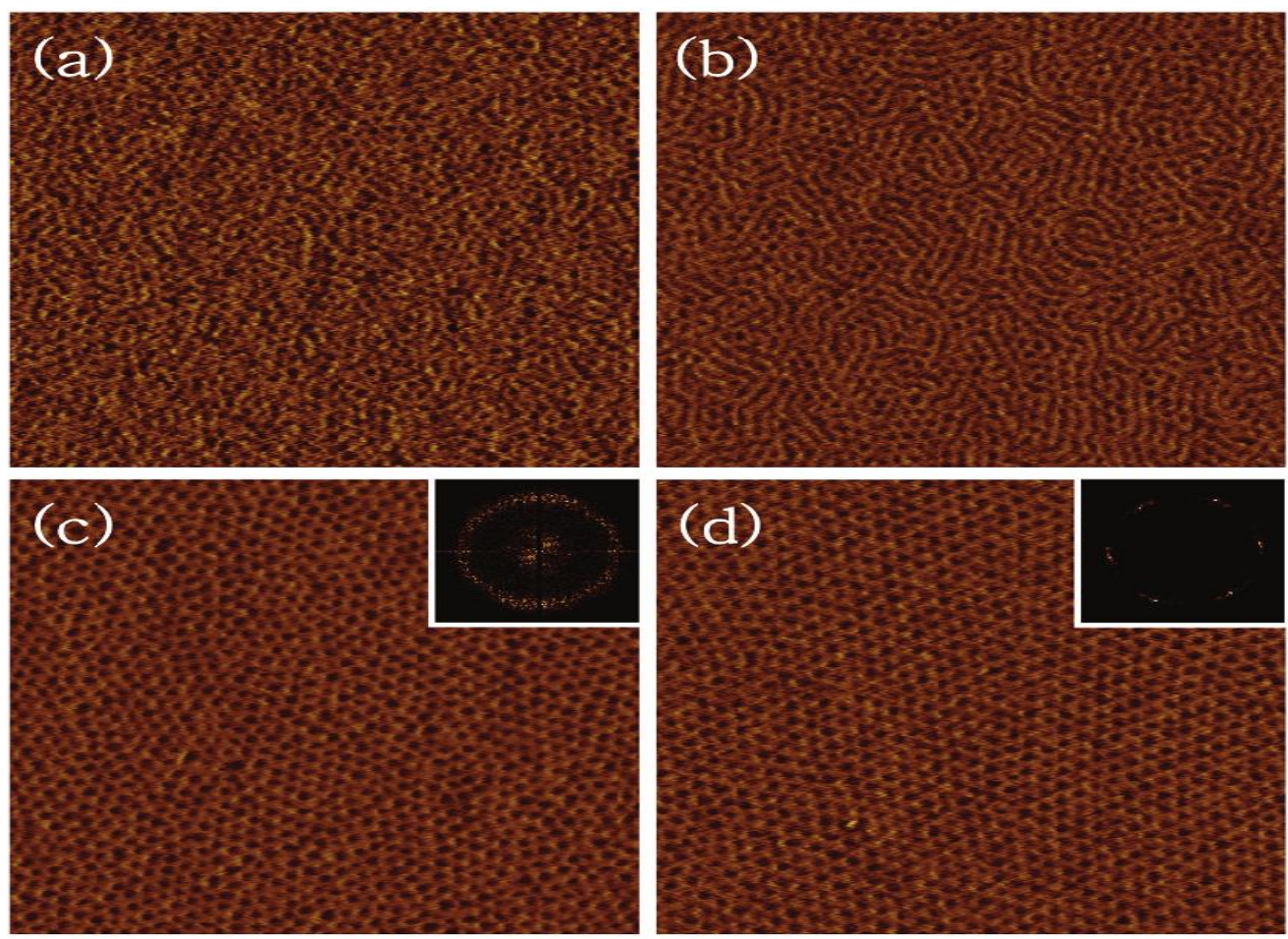

Figure 10. Images made using SFM of PS-b-PEO thin film after spin coating in a) air, b) toluene, c) toluene + water vapor, $d$ ) water vapor, scan areas are $1 \mu \mathrm{m}$ by $1 \mu \mathrm{m}$ (Reprinted with permission from S. Kim, R.M. Briber, A. Karim, R.L. Jones and H.C. Kim, Copyright 2007, Macromolecules.)

Kim and Hinsberg used ordering of domains achieved through self-assembled block copolymers as an etch mask to produce ordered nanostuctures. An example of nanostructures formed by block copolymers is shown in a cross sectional SEM image of nanopores on a polymer substrate; see Figure 11. These features were achieved using the thin film block copolymer as an etch mask. Some criteria considered were molecular weight of the copolymers, layer thickness, number of feature defects in the film, resolution of pores, and etching type [12]. 


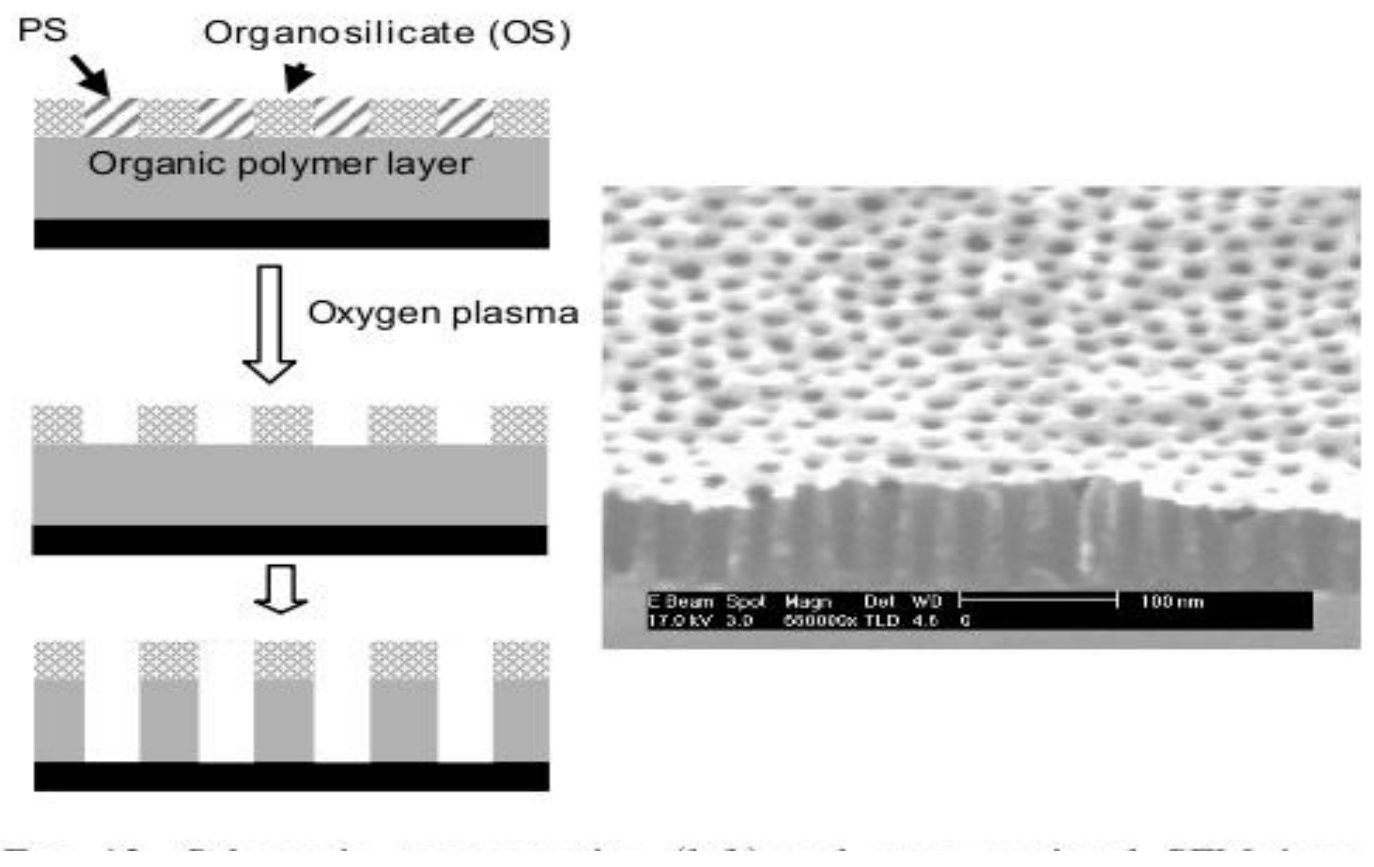

Figure 11. (Left) Schematic of how the block copolymer template acts as a etch mask. (Right) Cross sectional SEM image of nanopores etched on a polymer substrate using block copolymer as a template (Reprinted with permission from H.C. Kim and W.D. Hinsberg, Copyright 2008, J. Vac. Sci. Technol. A.)

According to the authors, dimensions of the microdomains are proportional to the molecular weight of the polymers. If the resolutions of the pores are not high enough, the pores will have irregular dimensions; this was also true for the number of feature defects in the thin film. The etching type must be such that the polymer template will corrode more easily at the desired domains to pattern the substrate [12].

\subsection{Electrospinning}

According to Li and Xia, electrospinning was another method of making materials with high surface area. The ability to make tunable nanofibers are dependent on several 
factors such as viscosity and elasticity of the polymer solution, the electrical conductivity, polarization, and surface tension of the solvent. Operational factors affect fiber characteristics as well. These factors are: electric field intensity, working distance, and polymer solution feed rate. An electrospinning setup involves a voltage source, conductive needle, collector, and a method of feeding the polymer solution or solutions in a controlled manner as shown in Figure 12 [13].

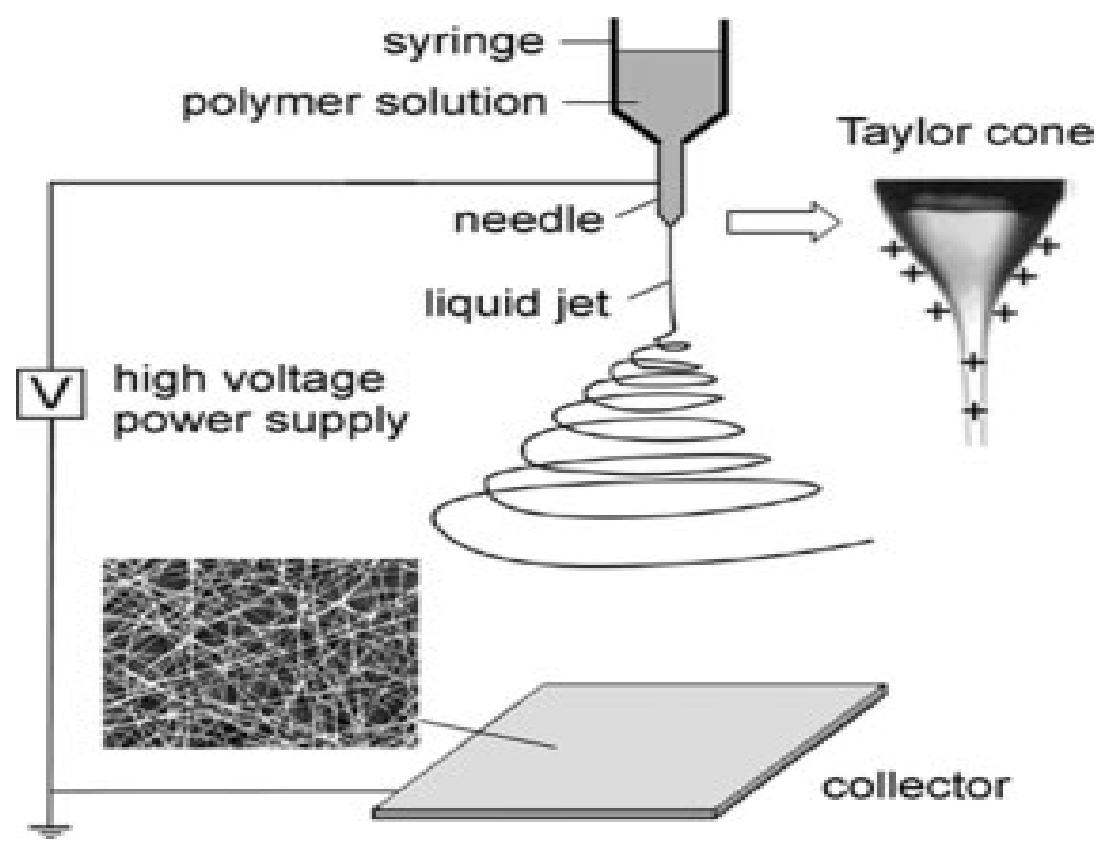

Figure 12. Basic setup for electrospinning (Reprinted with permission from D. Li and Y. Xia, Copyright 2004, Adv. Mater.)

Modification on the basic setup can be done to help create other features in the fibers such as hollow fibers. This was done by using two conductive needles, one inside the other. Each needle would contained a solution that was not soluble in one another. A solvent would then be introduced to dissolve the inner material following electrospinning. A schematic of a setup for electrospinning hollow fibers is shown in Figure 13 [13]. 


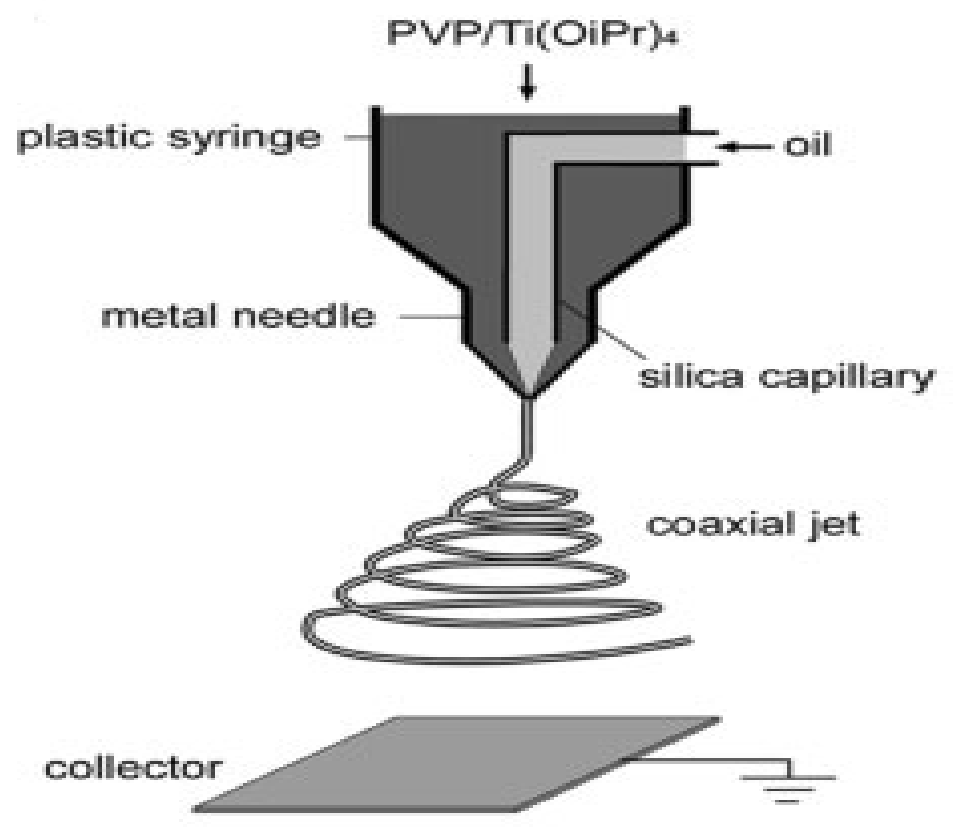

Figure 13. A modification of an electrospinning setup to make hollow fibers using two solutions (Reprinted with permission from D. Li and Y. Xia, Copyright 2004, Adv. Mater.)

Zussman et al. also investigated electrospinning using two polymers to form hollow fibers. The authors used polyacrylonitrile (PAN) as the shell and poly(methy methacrylate) (PMMA) as the core material. The PAN solution consisted of $12 \mathrm{wt} \%$ PAN in dimethylformamide (DMF). The viscosity and flow rate of the PAN solution were $6700 \mathrm{cP}$ and $0.2 \mathrm{~mL} / \mathrm{h}$, respectively. The PMMA solution was $15 \mathrm{wt} \%$ PMMA in a mixture of DMF/acetone (60:40). The viscosity and flow rates of the PMMA solution were $3800 \mathrm{cP}$, and $0.6 \mathrm{~mL} / \mathrm{h}$, respectively [14]. The use of two capillaries within other were used to electrospin hollow fibers. The inner and outer capillary had diameters of $0.42 \mathrm{~mm}$ and $0.64 \mathrm{~mm}$, respectively. The inner capillary used was 0.3 to $1 \mathrm{~mm}$ longer than the outer needle. This was done to allow the PAN solution to encapsulate the 
PMMA solution. The strength of the electric field used for electrospinning was 0.3 $\mathrm{kV} / \mathrm{cm}$. A collector made of aluminum foil was placed $18 \mathrm{~cm}$ from the core needle. Zussman et al. investigated two other methods for increasing nanofiber surface area. One involved using equal amounts of two non-miscible polymer solutions. The theory of using two non-miscible polymers was to introduce different domains in the electrospun fibers. When two polymer solutions are mixed in equal ratios, a highly porous structure could be achieved after electrospinning. Another method of creating porous fibers involved using separation of domains with block copolymers. Figure 14 shows porous nanofibers formed by the electrospinning of a solution made with two nonmiscible polymer solutions [13].

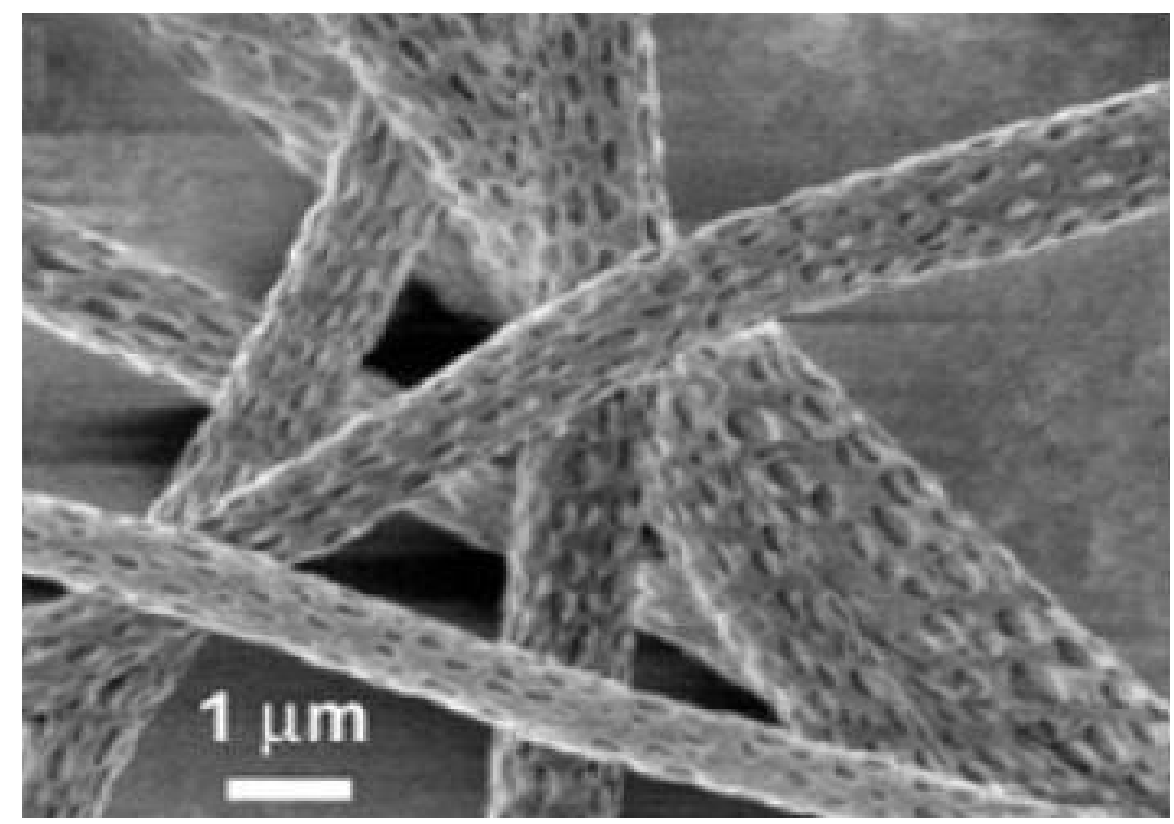

Figure 14. Porous polylactide in dichloromethane fibers investigated by SEM (Reprinted with permission from D. Li and Y. Xia, Copyright 2004, Adv. Mater.) 
Fridrikh et al., Reneker, and Yarin studied parameters that determine features of fibers including flow rate and distance from the collector. Physical characteristics such as viscosity and elasticity affected the features of fibers $[15,16]$. The lowest flow rates used to maintain continuous fibers lead to the smallest fiber diameters.

\subsubsection{Carbonization}

Investigated by Wen et al. were the affects of carbonization temperatures between $600^{\circ} \mathrm{C}$ to $1000^{\circ} \mathrm{C}$ on porous structures of carbon materials. The amount of carbon collected drops significantly for carbonization in the range of $600^{\circ} \mathrm{C}$ to $700^{\circ} \mathrm{C}$. However, above $700^{\circ} \mathrm{C}$ the amount of carbon material lost plateaus [17]. Capacitance is inversely proportional to carbonization temperature while conductivity is proportional to temperature. Electrical and gravimetric data for carbonized material is shown in Table 2 [17]. If carbonization occurs at an excessively high temperature, the resulting carbon material is brittle and have low capacitance. The optimum conditions for carbonization according to Wen et al. involve curing the polymer precursors at $225^{\circ} \mathrm{C}$ for 30 minutes, followed by carbonizing at $900^{\circ} \mathrm{C}$ for 30 minutes.

Table 2. Fiber characteristics after carbonization of nanoparticle glassy carbon [17].

\begin{tabular}{|c|c|c|c|c|c|}
\hline $\begin{array}{l}\text { Carbonization } \\
\text { Temperature }(\circ \mathrm{C})\end{array}$ & $\begin{array}{l}\text { Yield } \\
(\%)\end{array}$ & $\begin{array}{l}\text { Burn-off of } \\
\text { activation }(\%)\end{array}$ & Capacitance $(\mathrm{F} \mathrm{g}-1)$ & Conductivity $(\mathrm{S} \mathrm{cm}-1)$ & $\begin{array}{l}\text { ESR } \\
(\mathrm{cm} 2)\end{array}$ \\
\hline 600.0 & 59.1 & 16.2 & 190.0 & 4.3 & 0.9 \\
\hline 700.0 & 56.5 & 16.0 & 194.0 & 6.3 & 1.0 \\
\hline 800.0 & 55.3 & 12.5 & 179.0 & 7.0 & 0.0 \\
\hline 900.0 & 54.9 & 7.5 & 162.0 & 10.7 & 0.6 \\
\hline 1000.0 & 54.5 & 7.8 & 158.0 & 11.9 & 0.7 \\
\hline
\end{tabular}

Activated at $900 \circ \mathrm{C}$ for $15 \mathrm{~min}$. Electrode: $\Phi 16 \times 0.7 \mathrm{~mm}$. 
Ji et al. investigated making carbon nanofibers using a mixture of PAN and polypyrrole polymers. The polymer fibers were carbonized at $700^{\circ} \mathrm{C}$ in argon after the polymer underwent stabilization at $250^{\circ} \mathrm{C}$ in air. An electrochemical cell containing 2032 coin cells was used to investigate electrochemical properties of carbonized fibers. The coin cell setup consisted of:

- Argon filled glove box

- Copper foil as a working electrode

- Lithium ribbon counter electrodes

- Electrolyte

The electrolyte used by Ji et al. was made of $1 \mathrm{M}$ lithium hexafluorophosphate dissolved in a 1:1 ratio of ethyl carbonate and ethyl methly carbonate.

Charge/discharge measurements were performed in a potential range of $0 \mathrm{~V}$ to $2.80 \mathrm{~V}$. Surface morphologies were taken after carbon fibers underwent 50 charge/discharge cycles [18]. The authors concluded stabilization was needed prior to carbonization to increase the yield of carbon. Carbonization in air resulted in low carbon yield due to the breaking of carbon bonds to form $\mathrm{CO}_{2}$ gas $[17,18]$.

Frysz et al. confirmed the yield of carbon when carbonized in the presence of air would reduce the yield as carbonization temperature increased [19]. Figure 15 shows the plot of carbonization in nitrogen only, resulting in a rapid mass loss initially with a plateau after $200^{\circ} \mathrm{C}$ [19]. A complete mass loss of carbon during carbonization in nitrogen and air is shown by the thermal gravimetric analysis plot shown in Figure 16 [19]. 


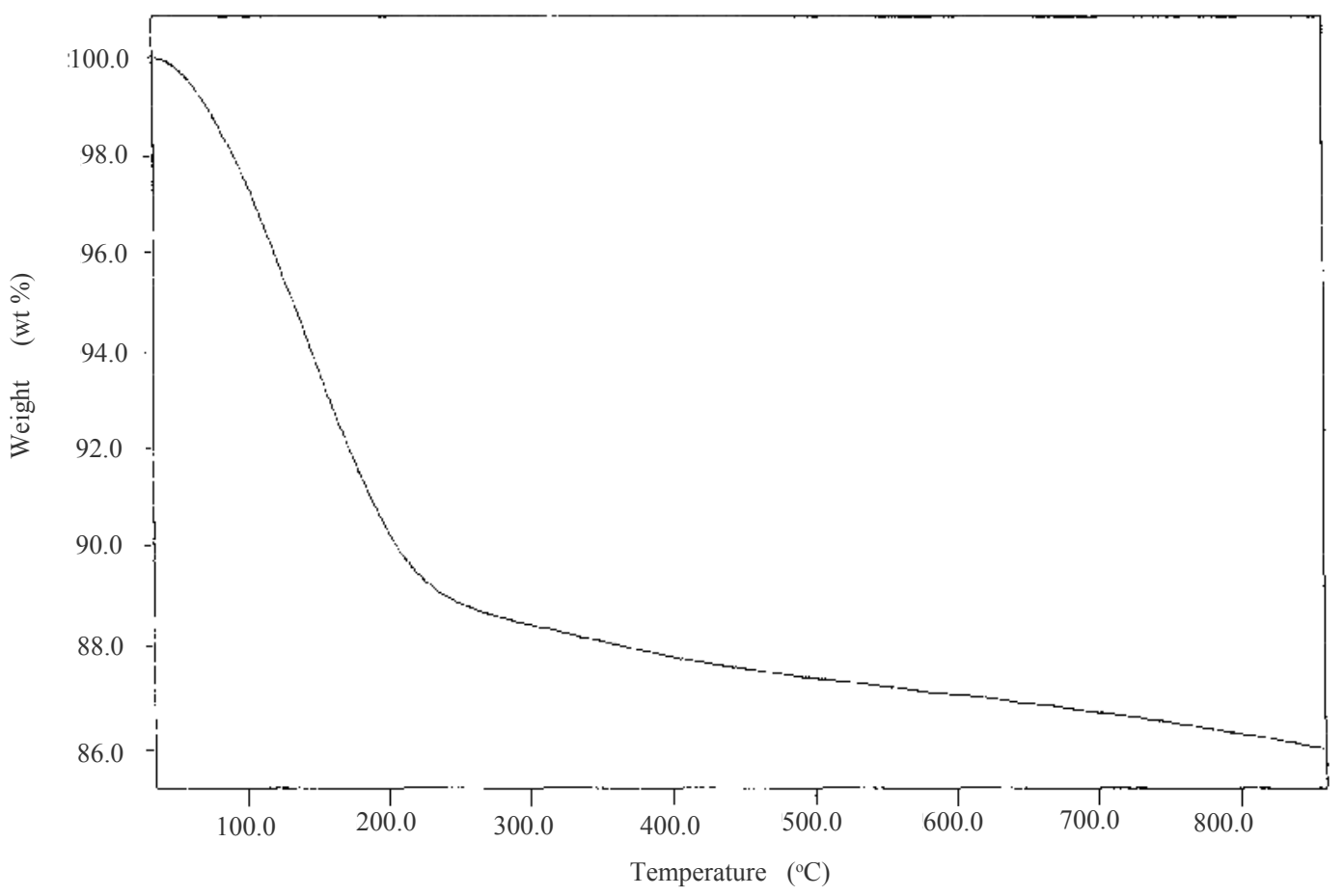

Figure 15. Thermal gravimetric data of phenolic based carbon in an atmosphere of nitrogen (Reprinted with permission from C.A. Frysz, X. Shui and D.D.L. Chung, Copyright 1997, Carbon.) 


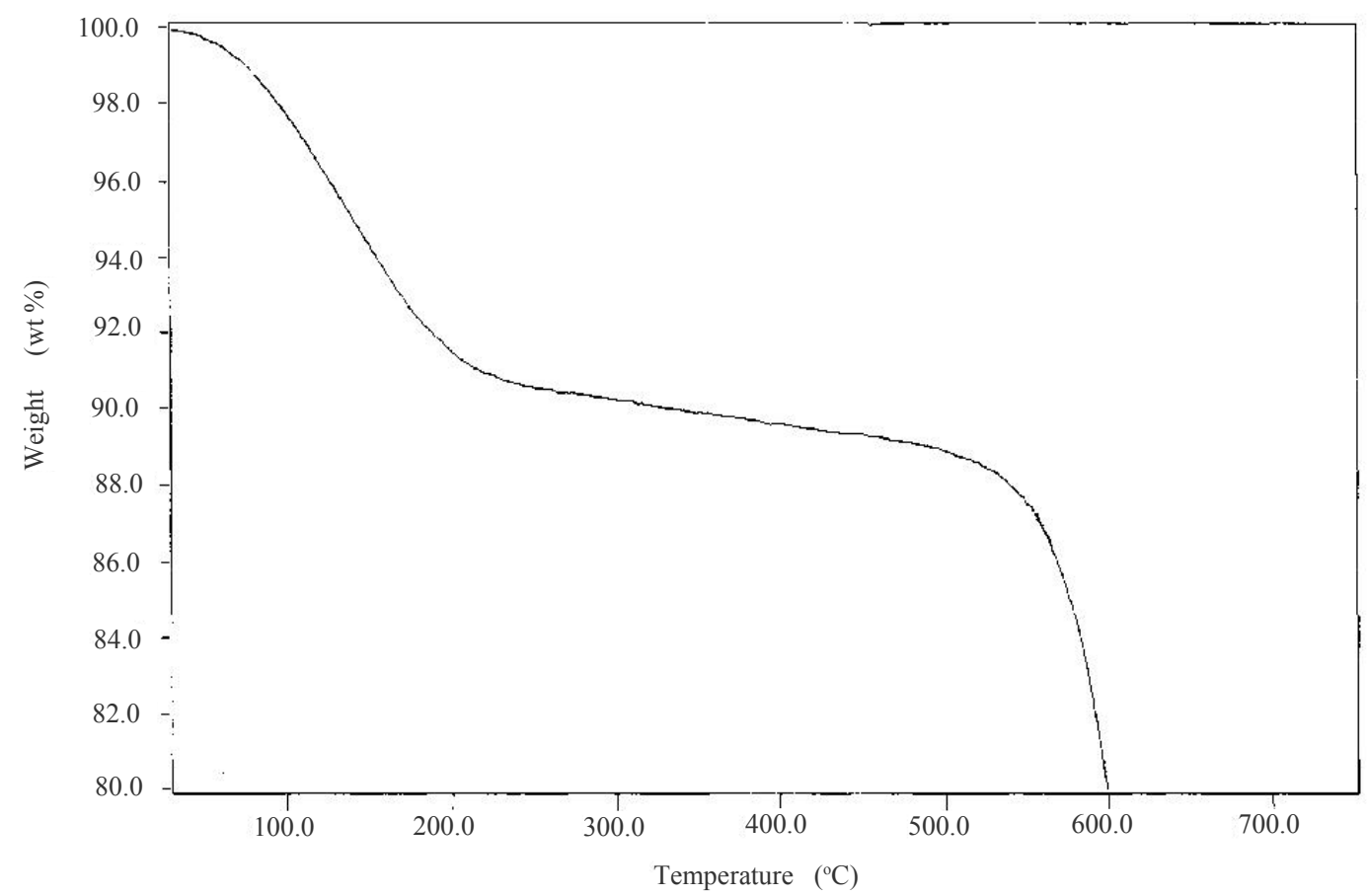

Figure 16. Thermal gravimetric data of carbonization of phenolic based carbon in an atmosphere of nitrogen and air (Reprinted with permission from C.A. Frysz, X. Shui and D.D.L. Chung, Copyright 1997, Carbon.)

\subsection{Electrochemical Investigation}

Wen et al. used $6 \mathrm{M} \mathrm{KOH}$ and placed their system under vacuum for $10 \mathrm{~h}$ before running the electrochemical investigation. The test capacitor used two facing nanoparticle glassy carbon electrodes separated by a membrane, and a nickel foam current collector. The carbon material underwent 30 cycles of charge/discharge, followed by conductivity measurements using a four-point probe [17].

Wang et al. investigated the electrical properties of carbon electrodes using cyclic voltammetry, impedance spectroscopy, and galvanostatic charge/discharge. Electrical investigations used a three electrode cell to run charge/discharge measurements. The three electrode test cell consisted of a foam nickel counter electrode, mercury/ mercury 
oxide reference electrode, and the carbon electrode [19]. The asymmetric supercapacitor was a sandwich two electrode cell, with carbon as the anode and nickel oxide as the cathode. This cell was used to run CV and impedance spectroscopy for 1000 cycles. The current density for this electrochemical capacitor was calculated to be $1 \mathrm{~A} / \mathrm{g}$ [20].

Morimoto et al. studied requirements of EDL capacitors using organic electrolytes. The potential of an activated carbon material used as an anode would experience as much as $3 \mathrm{~V}$ more than if it was used as a cathode [21]. The authors concluded that materials used as an anode must be resistant to anodic polarization to resist corrosion of the electrode. The coin cell used by the authors consisted of an organic electrolyte, nickel cathode, nickel foam separator, and an activated carbon anode. The potential applied between the anode and cathode was $2.80 \mathrm{~V}$ [21].

To perform electrochemical characterizations, the authors charged the cell to 5.50 $\mathrm{V}$ and allowed it to discharge with constant current. Equation 1 was used to calculate capacitance from the cyclic voltammetric measurements.

$$
\mathrm{C}=\mathrm{I}(\mathrm{t} / \Delta \mathrm{V}) \quad \text { Equation } 1[21]
$$

The following variables are represented in Equation 1: capacitance (C), discharge current (I), potential difference $(\Delta \mathrm{V})$, and discharging time $\mathrm{t}[21]$.

Prabaharan et al. studied the electrochemical behaviors of activated carbon electrodes used in supercapacitors. Their findings concluded carbon electrodes have their highest specific capacitance and energy when charged using low current densities. This was due to impedance of the material causing an initial discharge voltage drop. The voltage drop was directly associated to resistance of the system [22]. The resistance of 
the system increases with current density, causing power to be reduced. A plot showing the affects of current density on specific capacitance is shown in Figure 17. As current density decreases, capacitance increases as shown by the broader slopes, and the smaller voltage drop at the apex [22].

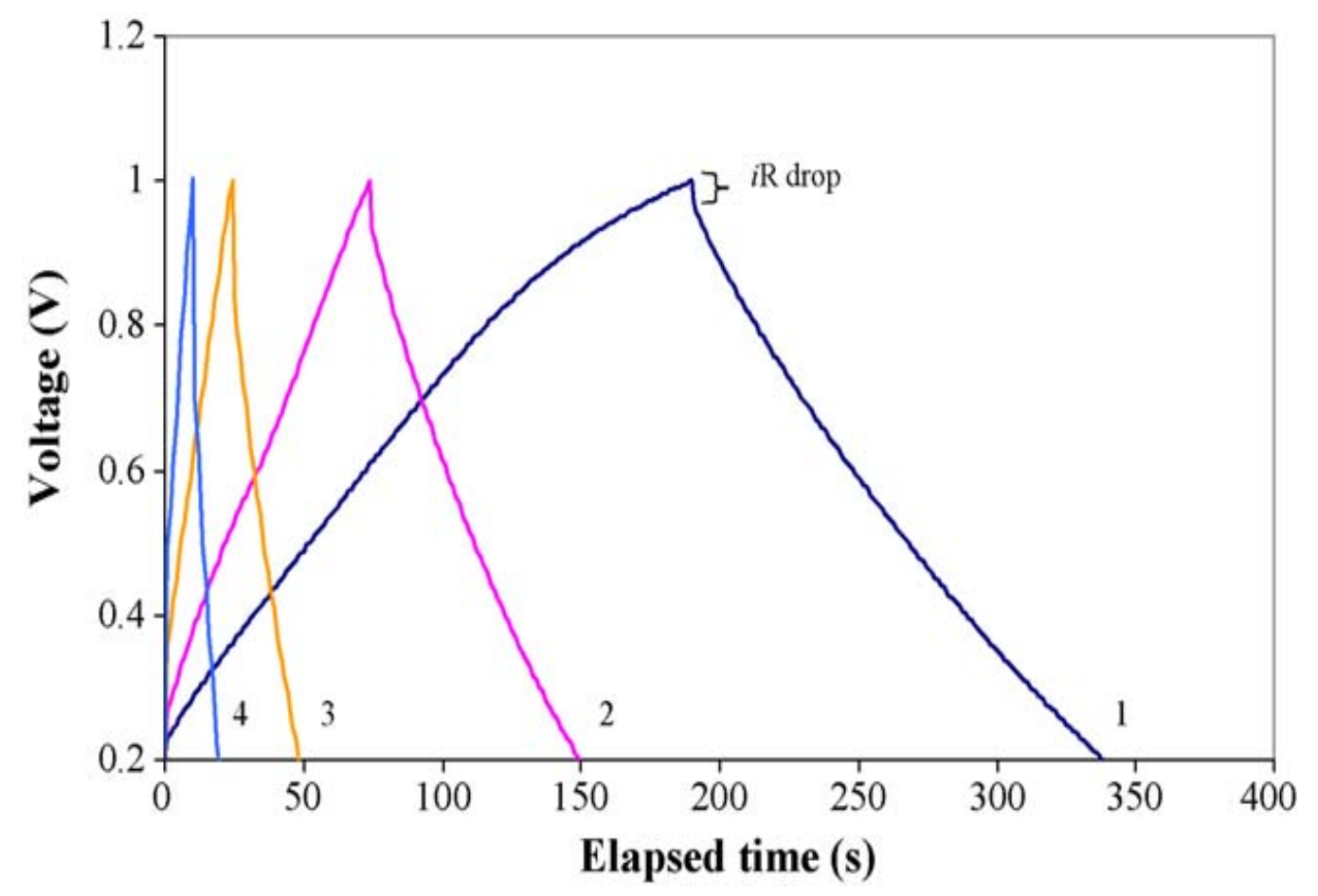

Figure 17. Increase in current density of electrodes results in a change of potential slope (Reprinted with permission from S. Prabaharan, R. Vimala and Z. Zainal, Copyright 2006, J. Power Sources.)

Frackowiak and Beguin also used impedance spectroscopy to investigate frequency dependence of activated carbon electrodes. Resistance of carbon electrodes as a function of frequency was measured by impedance spectroscopy, shown in Figure 18. Results indicated, resistance was affected at low frequencies, while a capacitance behavior was experienced at high frequencies. This behavior was also dependent on how many electrodes were used in the capacitor and electrode size [5]. At higher frequencies 
the carbon electrodes act in a purely capacitive behavior. At lower frequencies, the carbon electrode resistance was highly frequency dependent.

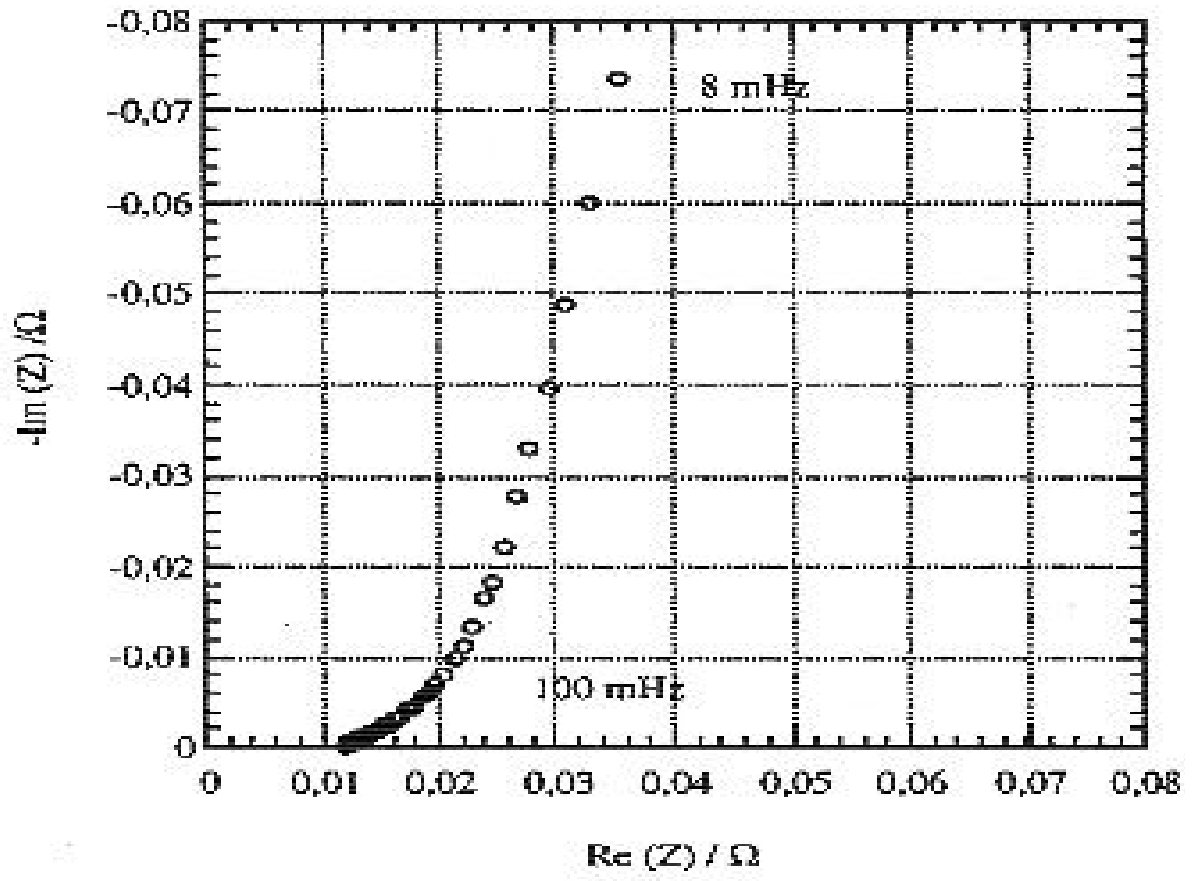

Figure 18. Impedance spectroscopy of 20 electrode capacitor showing exponential relationship as frequency was reduced (Reprinted with permission from E. Frankowiak and F. Beguin, Copyright 2001, Carbon.)

\subsection{Surface Characterization}

Surface area characterization of porous carbon electrodes was studied by Smith et al. using the Brunauer, Emmett, and Teller theory, also known as BET theory. The BET theory was based on the adsorption of isotherms onto the surface of porous materials [23]. Surface area was calculated by plotting the volume of adsorbed gas as a function of relative pressure. Relative pressure, $\mathrm{P} / \mathrm{P}_{\mathrm{o}}$, represented the equilibrium pressure of the system of adsorbed gas divided by the equilibrium pressure of a monolayer of adsorbed gas molecules [23]. Using the number of adsorbed gas molecules that formed a 
monolayer and the cross sectional area of an adsorbed gas molecule, $\mathrm{P} / \mathrm{P}_{\mathrm{o}} /\left(\mathrm{Xm}\left(1-\mathrm{P} / \mathrm{P}_{\mathrm{o}}\right)\right)$ as a function of $\mathrm{P} / \mathrm{P}_{\mathrm{o}}$ can be plotted and surface area calculated from the slope [23].

\subsection{Summary}

Improving electrical storage properties of supercapacitors to make them competitive to batteries drives research of energy storage devices. Batteries have been the main energy storage device for a century, yet have remained relatively unchanged. New technologies requiring higher power output and discharge/charge cycling have pushed the limits of current battery technology. Studies have found asymmetrical supercapacitors have the potential to be an upgrade from batteries. For supercapacitors to fill this role, researchers have been studying carbon as a possible electrode materials. Carbon can be utilized for its abundance and electrical characteristics. Processing parameters must be understood for carbon to be optimized for energy storage applications.

Specific for this project are the interactions between electrolytes and the surface of the electrode. Increasing surface area in an ordered fashion is investigated using an etch mask made of a block copolymer solution. The etch mask is utilized to expose the internal porous structures of glassy carbon in a homogeneous manner. Hybridization of etched glassy carbon will be preformed to increase surface area and introduce electrochemical properties. 


\section{CHAPTER THREE \\ OBJECTIVES}

The objectives of this thesis were to:

- Expose the nanostructures of glassy carbon electrodes to increase charge density

- Hybridize etched glassy carbon electrodes to increase surface area and introduce electrochemical reactions

- Fabricate polymer fibers with a diameter of under $100 \mathrm{~nm}$ using electrospinning

Electrical properties of glassy carbon-based electrodes such as, current density, and capacitance were investigated. Surface morphologies and compositions of electrodes were related to their electrical properties.

Using methods discussed in the literature to modify the surface of glassy carbon electrodes was the focus. The three methods for fabricating electrodes discussed in Chapter Two include:

- Using block copolymer as an etching mask on glass carbon to introduce ordered nanostructures to the surface.

- Hybridization of glassy carbon with metal oxides.

- Fabricating electrospun polymer fibers with high surface area as a potential carbon electrode.

Investigate the surfaces etched glassy carbon electrodes using SEM, TEM, and tapping mode AFM to evaluate the surface features. Using the information obtained through measurements using AFM software, SEM and TEM micrographs, surface area was calculated. Investigate the surface characteristics of electrospun polymer fibers using SEM. To determine charge density and capacitance of the glassy carbon-based electrodes, cyclic voltammetry will be used. The outcome resulted in the improvement of electrical storage properties of carbon-based electrodes. 


\section{CHAPTER FOUR MATERIALS AND METHODS}

\subsection{Introduction to Materials and Methods}

The objective was to increase capacitance and charge density of carbon-based electrodes by increasing surface area and hybridizing. Preamble experiments were done to determine processing conditions of enhancing surface area. Table 3 shows the experimental table for the surface modifications of glassy electrodes.

Table 3. Experimental matrix used to texturize glassy carbon electrode material.

\begin{tabular}{|c|c|c|c|}
\hline \multirow{1}{*}{ Glassy Carbon } & $\begin{array}{c}\text { Texturization } \\
\text { Method }\end{array}$ & Hybridization & Reason \\
\cline { 2 - 4 } & None & None & $\begin{array}{c}\text { Glassy carbon was used as the } \\
\text { control electrode for } \\
\text { electrochemical experiments. }\end{array}$ \\
\cline { 2 - 4 } & $\begin{array}{c}\text { Block } \\
\text { copolymer etch } \\
\text { mask on glassy } \\
\text { carbon }\end{array}$ & $\mathrm{TiO}_{2}$ & $\begin{array}{c}\text { To increase surface area by } \\
\text { introducing ordered porous } \\
\text { structures to glassy carbon } \\
\text { electrodes. }\end{array}$ \\
\cline { 2 - 4 } & $\begin{array}{c}\text { To increase the surface area of } \\
\text { etched glassy carbon electrodes by } \\
\text { introducing the porous structures of } \\
\text { TiO }\end{array}$ \\
\cline { 2 - 4 } & $\mathrm{Cu}_{2} \mathrm{O}$ & $\begin{array}{c}\text { To incorporate electrochemical } \\
\text { reactions and increase surface area } \\
\text { of etched glassy carbon electrodes. }\end{array}$ \\
\hline
\end{tabular}

No surface modification was performed on the unetched glassy carbon electrodes. Unetched glassy carbon was used as the control specimen for electrochemical experiments. Etched glassy carbon was used to determine the affect of increasing surface area on the electrical properties of glassy carbon. The reason for hybridizing with titania 
$\left(\mathrm{TiO}_{2}\right)$ was to increase surface area of etched glassy carbon. The porosity and electrical properties make $\mathrm{TiO}_{2}$ a good candidate for hybridizing glassy carbon. The capacitive properties of $\mathrm{TiO}_{2}$ allow charge to be stored on its surface. The porous structure of $\mathrm{TiO}_{2}$ gave more surface area for ions to become attached. Hybridizing etched glassy carbon electrodes with $\mathrm{TiO}_{2}$ increased available surface area for ion interactions. Hybridizing etched glassy carbon with cupric oxide $\left(\mathrm{Cu}_{2} \mathrm{O}\right)$ led to the combination of electrochemical and electric double layer properties. Cupric oxide has a porous structure, that allows more surface interactions with ions. The electrochemical reactions of $\mathrm{Cu}_{2} \mathrm{O}$ introduces battery-like properties to etched glassy carbon. As discussed in Chapter One, hybridizing capacitive materials with electrochemical materials will incorporate both properties into one electrode.

Parameters for texturization were determined by performing preamble experiments. One set of tests was used to determine what parameters for block copolymer solutions gave a defined porous structures. Parameters consisted of polymer concentrations and mixing ratios of polymer to organic silicate. According to Dekanski et al., better resolution leads to more easily accessible pores for ions [4]. Another set of tests were used to determine parameters, which gave good quality fibers from electrospinning. Parameters such as, viscosity of polymer solutions and types of solvents used were investigated. The final preamble experiments dealt with parameters for electrospinning such as: working distance, applied potential, and feed rate. 


\subsection{Preamble Experiments}

\subsubsection{Etch Mask}

On the surface of glassy carbon specimens, the block copolymer solution was deposited using spin-on-glass method as prescribed by Kim et al. The solution of block copolymers was made up of polystyrene block polyethylene oxide (PS-b-PEO), mixed with 1-methoxy-2-propyl-acetate (PGMEA) to make a $1 \mathrm{wt} \%$ solution. Higher weight percents of solutions did not yield desired pore resolutions. The molecular weights of the block copolymer components are $20 \mathrm{~kg} / \mathrm{mol}$ and $14 \mathrm{~kg} / \mathrm{mol}$ for polystyrene (PS) and poly(ethylene oxide) (PEO), respectively. Using larger molecular weight polymers gave larger pore diameters. Smaller molecular weight polymers gave smaller pore diameter. However, the pores resolutions using too low molecular weight polymers was difficult to control. Block copolymer solutions were made up of $1 \mathrm{wt} \%$ PS-b-PEO solution mixed with $1 \mathrm{w} \%$ organic silicate (OS) in propylene glycol propyl ether (PGPE) solution. Mixing ratios consisted of 50/50, 40/60, and 30/70 for $1 \mathrm{wt} \%$ PS-b-PEO and $1 \mathrm{wt} \%$ organic silicate solution, respectively. Organic silicate was used because it was miscible with PEO and not PS to form the PEO+OS matrix and PS pores.

Block copolymer solutions were deposited on glassy carbon substrates and left in a solvent vapor for 30 seconds before spin coating. Specimens were spun at a rate of $2000 \mathrm{rpm}$ for 45 seconds under the solvent atmosphere. The coated glassy carbon specimens were annealed at $180^{\circ} \mathrm{C}$ for 20 minutes under an atmosphere of nitrogen. Porous structures of the spun-on etch mask films were previously studied $[10,11]$. Glassy carbon specimens coated with the etch mask were etched using a low power 
anodizing oxygen ion etch. Six ion pulses for a duration of 15 seconds each was used to etch glassy carbon. The etching procedure exposed glassy carbon's internal porous structure. After the specimens were etched, the remaining etch masks were removed using an acid wash. The acid wash consisted of soaking etched electrodes in $4.8 \mathrm{wt} \%$ hydrofluoric acid for five minutes, followed by double rinsing in deionized water. Freshly cleaned specimens were dried using compressed nitrogen gas and left under a hood over night to dry thoroughly. A schematic, shown in Figure 20, represents steps used to create porous glassy carbon electrodes.

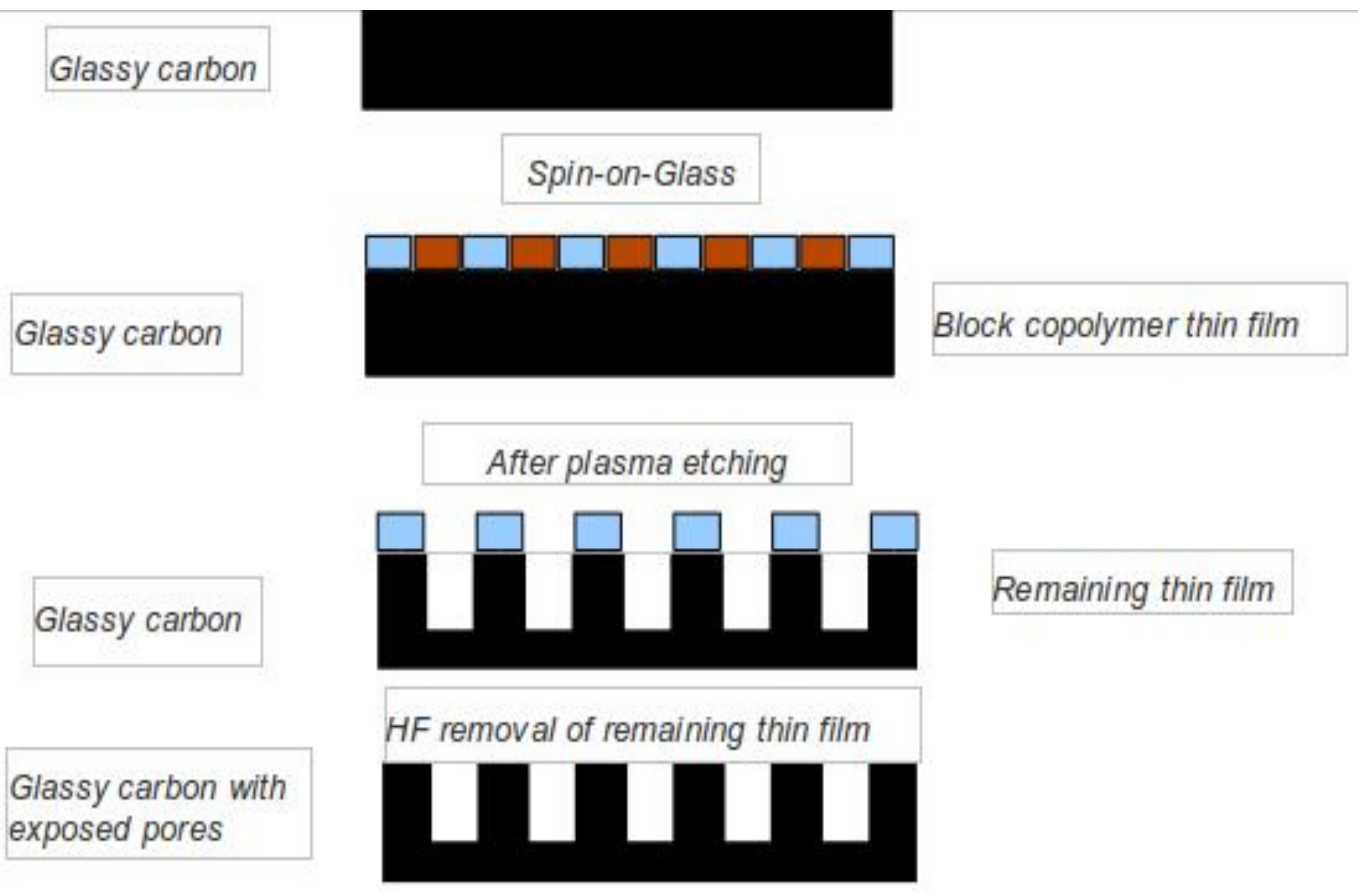

Figure 19. Schematic of steps used to expose internal pores of glassy carbon electrodes. Appropriate mixtures of block copolymer and organic silicate (OS) solutions were required to produce domains for use as an etching mask. Due to mixing of PEO and OS, PS was constricted to form pores. When an excess of OS was used, the PEO+OS matrix 
swells. Swelling of the PEO+OS matrix resulted in polystyrene pores becoming partially disassociated from the matrix. When an insufficient amount of OS was used, PS would not be constricted enough to form pores. The etch mask would be a disordered array of PS in the PEO+OS matrix.

\subsubsection{Electrospinning Fibers}

For electrospun specimens the dimensions and quality of the spun fiber are dependent on the working distance, applied potential, viscosity of the polymer solutions, feed rate, and polarity of the solvent [13-16]. A conducting needle and aluminum foil wrapped around a rotating drum were used as the needle and collector, respectively. Polymer solutions were held in a stainless steel syringe during electrospinning. The working distance used in the experiment was $10 \mathrm{~cm}$. A potential between $7.5 \mathrm{kV}$ and 12 $\mathrm{kV}$ was used to accelerate the polymer solution from the tip to the collector. Viscosity and flow rates used in the experiments were low enough to allow solution to flow through the needle without excess, but high enough to maintain electrospinning of fibers.

\subsection{Specimen Surface Modification}

\subsubsection{Glassy Carbon}

Surface of glassy carbon was cleaned using compressed nitrogen gas prior to polymer solution deposition. The block copolymer solution used to form the etch mask consisted of a 30/70 ratio of $1 \mathrm{wt} \%$ poly(styrene-block-(ethylene oxide))/1-methoxy-2propyl-acetate (PS-b-PEO/PGMEA) and $1 \mathrm{wt} \%$ organic silicate/propylene glycol propyl ether (OS/PGPE), respectively. The molecular weight of PS-b-PEO used was $20 \mathrm{~kg} / \mathrm{mol}$ for PS and $14 \mathrm{~kg} / \mathrm{mol}$ for PEO. Five drops of the block copolymer solution were 
deposited using a plastic syringe fitted with a $0.2 \mu \mathrm{m}$ filter. A solvent was deposited onto a piece of tissue paper, which was inserted in the bottom of a glass beaker. The beaker was inverted over the specimen to form a solvent vapor atmosphere. This vapor atmosphere interacted with the block copolymer solution and formed PS pores. Polystyrene pores were formed due to the dissolution of PS and not of PEO in the vapor. Exposure to the solvent atmosphere began 30 seconds prior to spinning and remained throughout the spinning process. Annealing of the block copolymer coated specimens was performed using the annealing process described in the preamble experimental section. Once annealing was complete, the etch mask was finally formed on the surface of glassy carbon.

After the etch mask was applied to seven glassy carbon electrodes, they underwent etching. The ion etch recipe used consisted of: low power, anodizing oxygen ion etch, with six cycles of 15 second pulses. Removal of the remaining etch mask involved submerging each etched specimen in $10 \mathrm{ml}$ of $4.8 \mathrm{wt} \%$ hydrofluoric acid (HF) solution for five minutes, followed by double rinsing in deionized (DI) water. Specimens were dried using compressed nitrogen gas and left overnight under the hood.

\subsubsection{Hybridization}

Four etched glassy carbon specimens were hybridized by applying a catalyst to their surfaces. The catalysts used were titania $\left(\mathrm{TiO}_{2}\right)$ and cupric oxide $\left(\mathrm{Cu}_{2} \mathrm{O}\right)$. Two etched glassy carbon specimens were hybridized with titania and two were hybridized with cupric oxide. Titania was used because of its capacitive electrical properties and its porous structure. Applying $\mathrm{TiO}_{2}$ introduced features to add surface area to etched glassy 
carbon. Etched glassy carbon specimens were hybridized with $\mathrm{Cu}_{2} \mathrm{O}$ to introduce electrochemical charge storage to the electric double layer characteristics of glassy carbon electrodes.

Hybridizing glassy carbon with $\mathrm{TiO}_{2}$ was done by applying five drops of $6 \mathrm{wt} \%$ $\mathrm{TiO}_{2} /$ PGPE onto glassy carbon specimens and spin coating at 2000 RPM for 45 seconds in air. Titania was applied using a plastic syringe tipped with a $0.2 \mu \mathrm{m}$ filter. The specimens were annealed by baking in an aluminum boat starting at $27^{\circ} \mathrm{C}$ and increasing to $450^{\circ} \mathrm{C}$ over 60 minutes. Temperature was held at $450^{\circ} \mathrm{C}$ for 90 minutes, and allowed to cool to $27^{\circ} \mathrm{C}$ slowly. Baking of $\mathrm{TiO}_{2}$-hybridized etched glassy carbon was done in an atmosphere of nitrogen.

Hybridization of glassy carbon specimens with $\mathrm{Cu}_{2} \mathrm{O}$ was done by applying five drops of $2 \mathrm{wt} \%$ cupric oxide/isopropanol $\left(\mathrm{Cu}_{2} \mathrm{O} / \mathrm{IPA}\right)$ using a plastic syringe tipped with a $0.2 \mu \mathrm{m}$ filter. This was followed by spin coating the $\mathrm{Cu}_{2} \mathrm{O}$ on etched glassy carbon at 2000 RPM for 45 seconds. The specimens were annealed by baking in a covered aluminum boat, at $600^{\circ} \mathrm{C}$ for 60 minutes. Annealing of $\mathrm{Cu}_{2} \mathrm{O}$-hybridized etched glassy carbon was done in air.

\subsubsection{Electrospun Fibers}

The electrospun polymer solution consisted of $1 \mathrm{wt} \%$ poly(acrylonitrile-co-methyl acrylate)/dimethyl sulfoxide (co-PAN/DMSO). The $1 \mathrm{wt} \%$ co-PAN/DMSO solution was mixed at $70^{\circ} \mathrm{C}$ with a magnetic stirrer for three hours. The polymer solution was fed through a 30 gauge needle with a constant flow rate. Working distance during electrospinning was $10 \mathrm{~cm}$. Applied potential between the conductive needle and the 
aluminum collection plate was $7.5 \mathrm{kV}$. Carbonization of the electrospun fibers was done in a tube furnace after the solvent dried overnight in air. The dried electrospun fibers were first stabilized at $250^{\circ} \mathrm{C}$ in air for one hour, followed by pumping in nitrogen for one hour to remove oxygen from the system. Carbonization was conducted at $700^{\circ} \mathrm{C}$ for one hour under a continuous flow of nitrogen gas. The carbonized material was left to cool overnight in the tube furnace under flowing nitrogen gas.

\subsection{Characterization}

\subsubsection{Surface}

Specimens were investigated using tapping mode AFM before and after etching to compare pore resolutions of the etch mask to the etched surface. A total of three etched glassy carbon specimens were investigated using AFM. Each specimen was investigated in three different locations on their surfaces. Pore diameters were measured manually using AFM software. Surface morphologies of etched glassy carbon electrodes were examined using SEM and TEM. A total of three etched glassy carbon electrodes were inspected using SEM in three locations on their surfaces. Surface morphologies of four hybridized carbon specimens were investigated using TEM. Two specimens each of $\mathrm{TiO}_{2}$-hybridized and $\mathrm{Cu}_{2} \mathrm{O}$-hybridized etched glassy carbon electrodes were evaluated with TEM. Electrospun fibers were investigated using SEM prior to carbonization. Fiber diameters were measured manually using SEM software in four locations. 


\subsubsection{Electrochemical Characterization}

The electrochemical characterizations were performed on seven glassy carbon specimens. As shown in Figure 20 was the setup used to perform CV measurements on the seven electrodes.

Experimental setup for CV measurements consisted of:

- Teflon electrode holder with $1.69 \mathrm{~cm}^{2}$ openings to expose electrode surfaces

- Platinum foil counter electrode

- Silver/silver chloride $(\mathrm{Ag} / \mathrm{AgCl})$ reference electrode

- Electrode of interest as the working electrode

- $1 \mathrm{M} \mathrm{KOH}$ electrolyte

- Potential source

- Glass beaker

The potential range and sweep rate used for $\mathrm{CV}$ measurements were $0 \mathrm{~V}$ to $-0.3 \mathrm{~V}$ to $0.6 \mathrm{~V}$ and $10 \mathrm{mV} / \mathrm{sec}$, respectively. All $\mathrm{CV}$ measurements were performed at room temperature and in air. Capacitance was calculated using Equation 1 from Morimoto et $a l$. in Chapter Two. Applied current was represented by I, $\Delta \mathrm{V}$ represents the change in potential over the applied potential range, and $t$ was the time it took to sweep across the potential range [21]. 


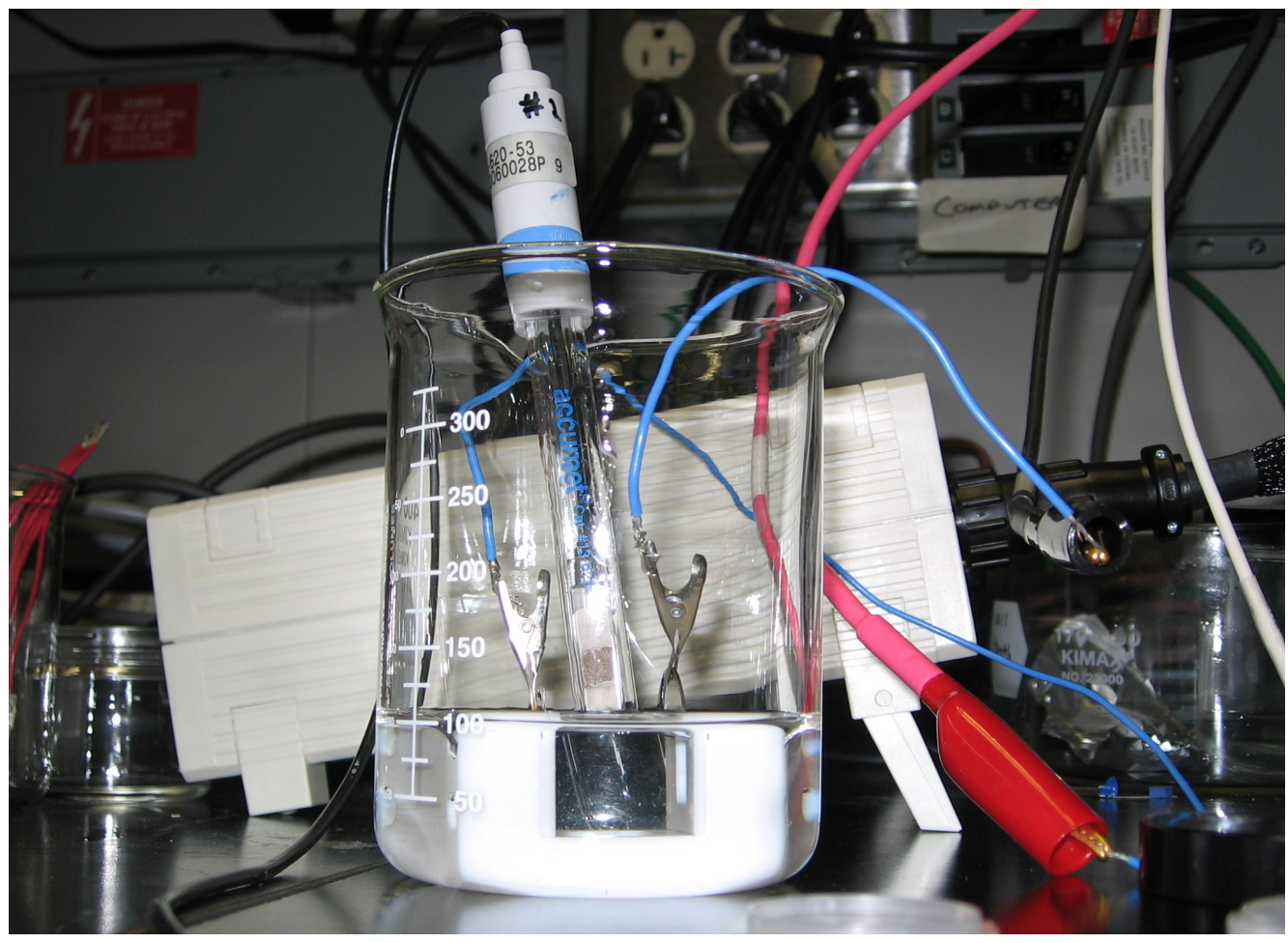

Figure 20. Experimental setup used for cyclic voltammetric measurements. Equipment pictured included: Teflon electrode holder, glassy carbon working electrode, platinum counter electrode, and silver/silver chloride $(\mathrm{Ag} / \mathrm{AgCl})$ reference electrode. 


\section{CHAPTER FIVE \\ RESULTS}

As shown in Table 3 in Chapter Four, four types of electrodes were fabricated. Unetched glassy carbon was the control for the electrochemical experiments. The glassy carbon electrodes were texturized by using an etch mask to etch selected parts of the surface. The etch mask was made of the following: 30/70 ratio of $1 \mathrm{wt} \%$ poly(styreneblock-(ethylene oxide))/1-methoxy-2-propyl-acetate (PS-b-PEO/PGMEA) and $1 \mathrm{wt} \%$ organic silicate/propylene glycol propyl ether (OS/PGPE), respectively. The etching recipe used to expose the surface of glassy carbon consisted of a low power, anodizing oxygen ion etch, for six cycles at 15 seconds per pulse.

Cyclic voltammetry was used to investigate the electrical properties of the carbonbased electrodes. The experimental setup consisted of:

- Electrode of interest as the working electrodes

- Platinum counter electrode

- Silver/silver chloride reference electrode

- Electrode holder made of Teflon

- $1 \mathrm{M}$ potassium hydroxide electrolyte

Two methods were used to hybridize the etched glassy carbon electrodes. One method of hybridizing etched glassy carbon was discussed in Chapter Four. To hybridize etched glassy carbon with titania, five drops of $6 \mathrm{wt} \% \mathrm{TiO}_{2} / \mathrm{PGPE}$ was applied to etched glassy carbon electrodes and spun-on. The electrodes were spun coated at 2000 RPM for 45 seconds to evenly distribute titania on the etched glassy carbon electrode's surface. The specimens were annealed in an aluminum boat beginning at $27^{\circ} \mathrm{C}$. The temperature 
was increased to $450^{\circ} \mathrm{C}$ over 60 minutes and held for 90 minutes. To hybridize etched glassy carbon with cupric oxide, five drops of $2 \mathrm{wt} \%$ cupric oxide/isopropanol $\left(\mathrm{Cu}_{2} \mathrm{O} / \mathrm{IPA}\right)$ was applied to the etched glassy carbon and spun-on. The specimens were spun coated at 2000 RPM for 45 seconds to evenly distribute cupric oxide on the etched glassy carbon electrode's surface. The specimens were annealed in a covered aluminum boat at $600^{\circ} \mathrm{C}$ for 60 minutes.

Titania was used to hybridize etched glassy carbon due to its porous and capacitive characteristics. The porosity of titania adds features to the surface and pore walls of etched glassy carbon. The capacitive properties allow charge to be stored in an electric double layer. The adding of features increases the electric double layer and results in higher charge storage density for the electrodes.

Cupric oxide was used to hybridize etched glassy carbon because of its electrochemical properties and porosity. Cupric oxide attaches to the surface and pore walls of etched glassy carbon. With the high surface area of etched glassy carbon, more cupric oxide can be utilized. More cupric oxide utilized, results in increased interactions with the electrolyte and a higher electrochemical reactivity.

Prior to etching, glassy carbon electrodes coated with the etch mask were investigated with AFM. The pore's diameters of etched glassy carbon was measured manually with AFM software. Measurements were taken from seven etch mask coated glassy carbon electrodes at three locations each. Pores of etched glassy carbon electrodes were measured manually using AFM software. Measurements were taken from seven etched glassy carbon electrodes at three locations each. In addition, surfaces of the seven 
etched glassy carbon electrodes were also investigated with SEM in three locations each. Pore profiles in etched glassy carbon electrodes were investigated using TEM.

Mats of electrospun fibers were investigated as a potential electrode material with high surface area. However, due to the brittleness of carbonized electrospun fibers, electrochemical experiments were not performed. As a result, only the diameters of electrospun fiber were investigated at this time. Electrospun fibers were fabricated using $1 \mathrm{wt} \%$ poly(acrylonitrile-co-methyl acrylate)/dimethyl sulfoxide (co-PAN/DMSO). The fiber diameter was measured at four locations manually using SEM software. These results are included at the end of this chapter.

\subsection{Surface Analysis of Carbon Electrodes}

Using the tapping mode on the AFM, etch mask-coated glassy carbon electrodes were investigated to determine their surface characteristics. Results from AFM micrographs indicate the etch mask contains domains in a hexagonal array. Pores of the etch mask have an average diameter calculated to be approximately $18 \mathrm{~nm}$ with a standard deviation of $4 \mathrm{~nm}$. The diameter of pores in the etch mask were manually measured with 25 pores using AFM software. In Figure 21, light (gold) coloration indicates high regions, while the dark (red) regions indicate lower regions. 


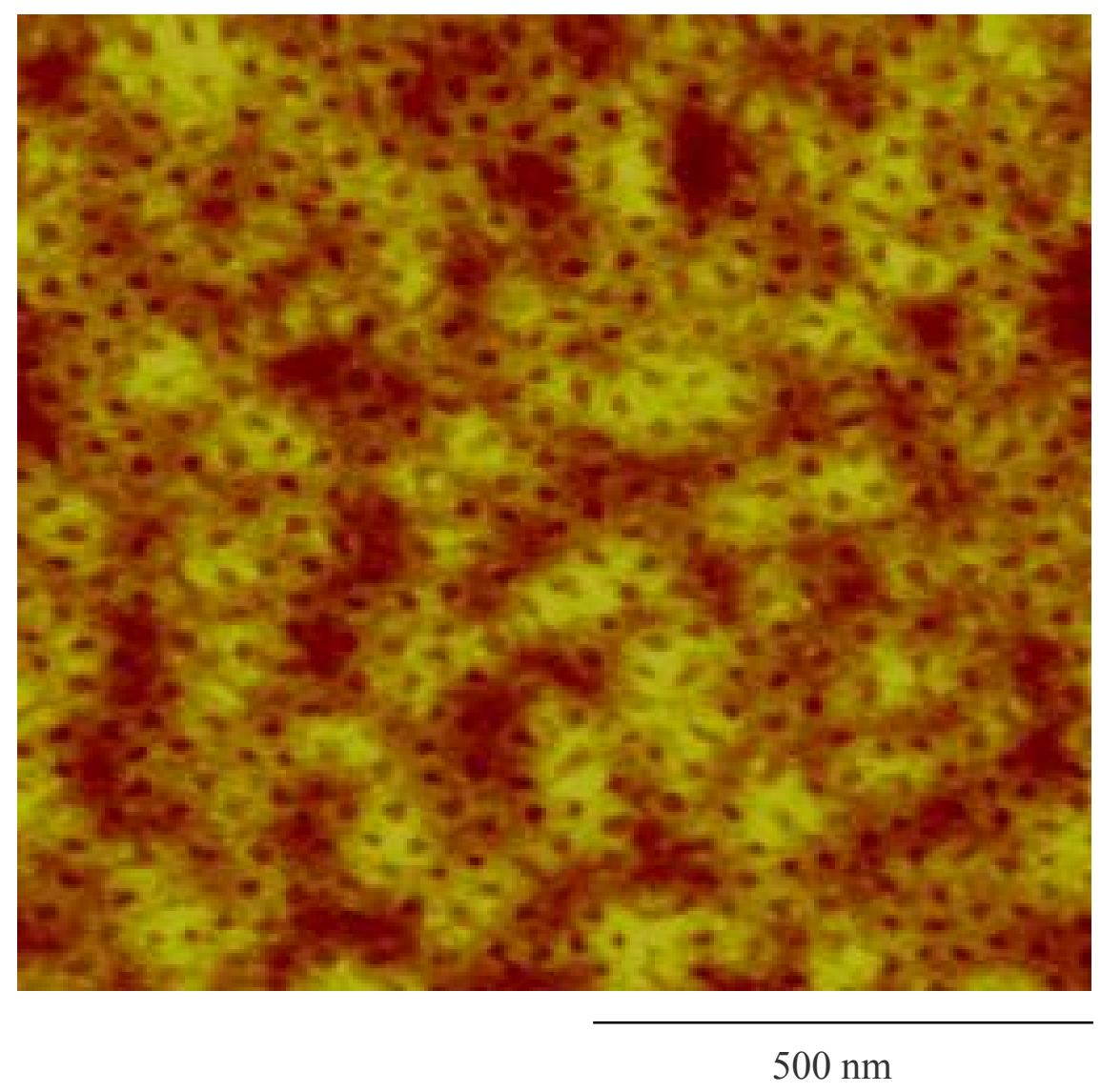

Figure 21. Etch mask-coated glassy carbon electrode, obtained by AFM.

When glassy carbon electrodes were etched using the etch mask, a hexagonal array of pores were observed on the surface, matching those observed on the etch mask. Using tapping mode AFM, the etch mask coated glassy carbon was investigated. Hexagonal arrays of pores were observed as shown in Figure 22. The porous structures resulting from etching the surface with the etch mask was investigated using AFM and SEM. Surface characteristics observed with AFM and SEM are shown in Figures 22 and 23 , respectively. The average pore diameter was determined to be $20 \mathrm{~nm}$ with a standard deviation of $6 \mathrm{~nm}$ by manually measuring 25 pores using AFM software. The number of 
pores in a $1 \mu \mathrm{m}^{2}$ was determined by manually counting pores from Figure 23 . The density of pores was calculated to be 583 pores $/ \mu \mathrm{m}^{2}$. Using the average diameter of the pores and number of pores, surface area removed during etching was calculated.

Surface area added by etching was calculated using the surface area of cone pores etched into the surface.

From Figure 22, pores are observed in hexagonal arrays. Dark (red) pores are observed with light (gold) region separating pores. These match the porous structure seen of the etch mask shown in Figure 21. The dark (red) regions represent the AFM tip moving deep into the specimen due to the lack of material. Light (gold) regions represent the AFM tip being moved up due to material lifting the tip. Large regions of light (gold) regions were observed in random locations. This was most likely caused by particles obstructing the movement of the AFM tip. The random nature of the light (gold) regions indicate they are not a result of a damaged tip. 


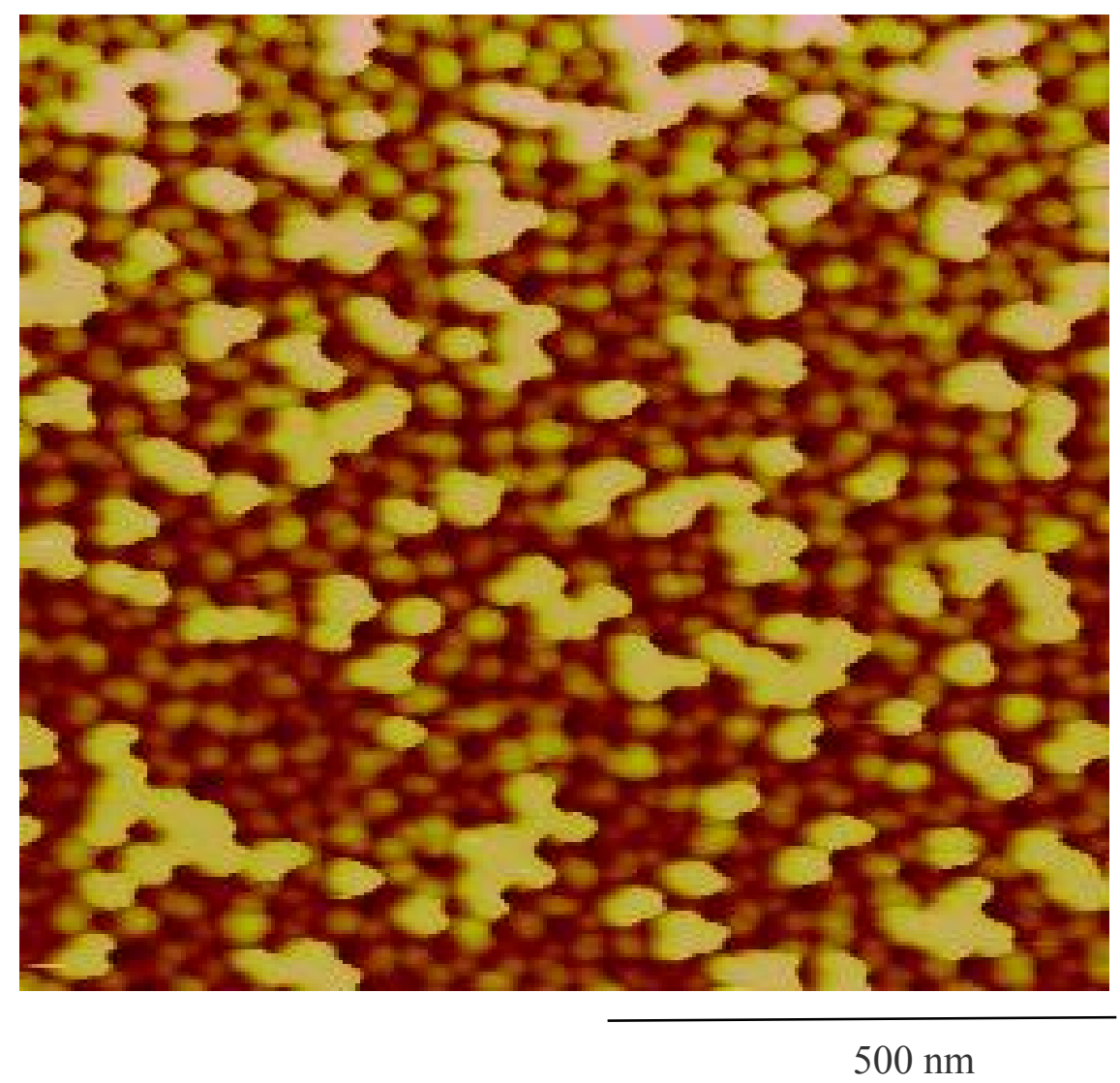

Figure 22. Surface characteristics of etched glassy carbon electrodes with etch mass removed, obtained by AFM.

Comparing the SEM image in Figure 23 to the AFM image in Figure 22 shows none of the random high regions seen by AFM. Pores in the surface of etched glassy carbon are clearly seen in hexagonal arrays. The pore shapes are mostly circular as viewed from top-down. Reasons for high regions detected by AFM may be indicated by the white coloring in SEM. The white coloring in SEM indicates charging of the material. Since polymers charge under SEM, these regions may contain remnant etch mask. The etch mask likely became attached to the AFM tip and obstructed its movement, resulting in high regions. 


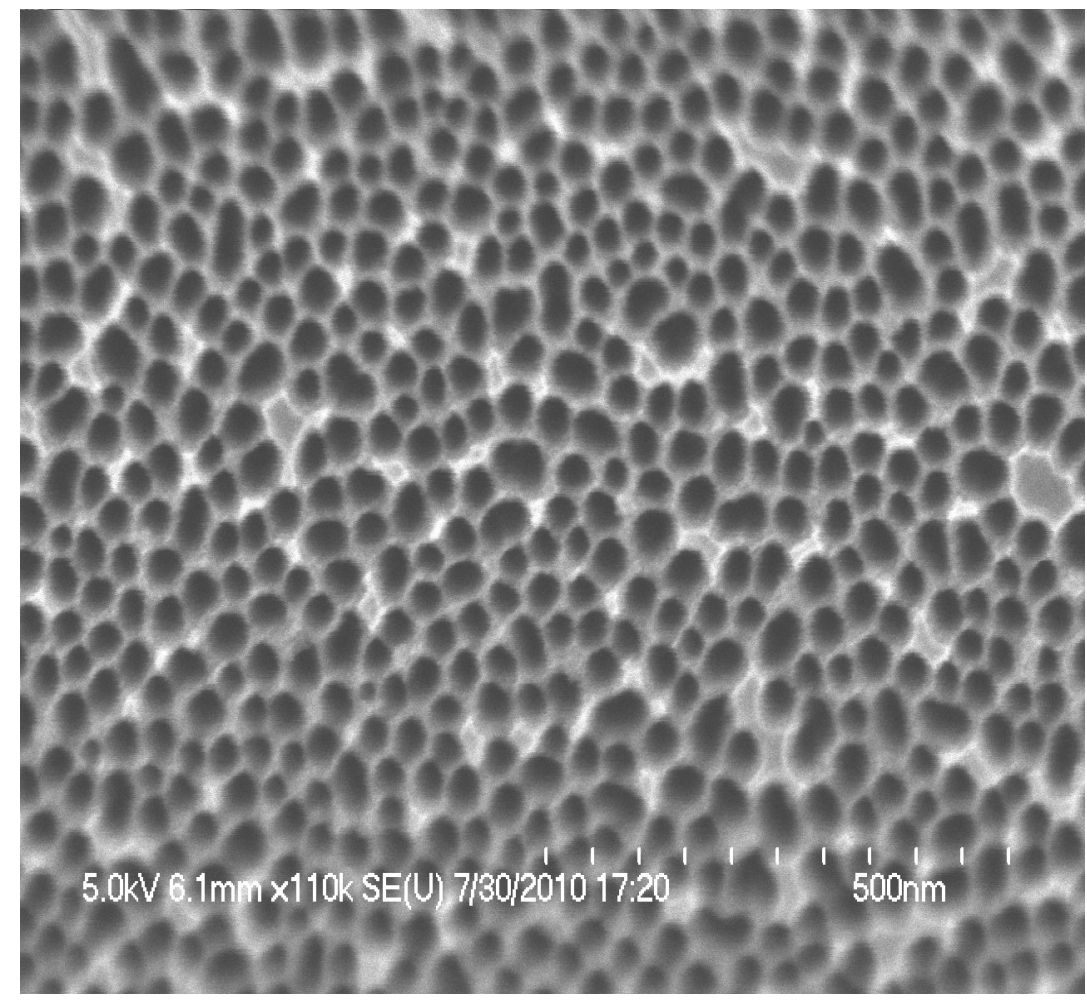

Figure 23. Surface characteristics of etched glassy carbon electrodes, with etch mask removed, obtained with SEM.

Cone pores resulting from etching were observed by cross sectional TEM in Figure 24. Pores etched into glassy carbon using the etch mask, resulted in cone shaped pores. The average pore depth was determined to be $151 \mathrm{~nm}$ with a standard deviation of $12 \mathrm{~nm}$ manually measuring 10 pores using the scale bar and a ruler. The surface area of cone pores was added to the remaining surface area of etched glassy carbon to calculate the total surface area. The pore density of etched glassy carbon electrodes appears to be homogeneous. The homogeneity of the pores allowed the surface area to be calculated in a simplified manner. 


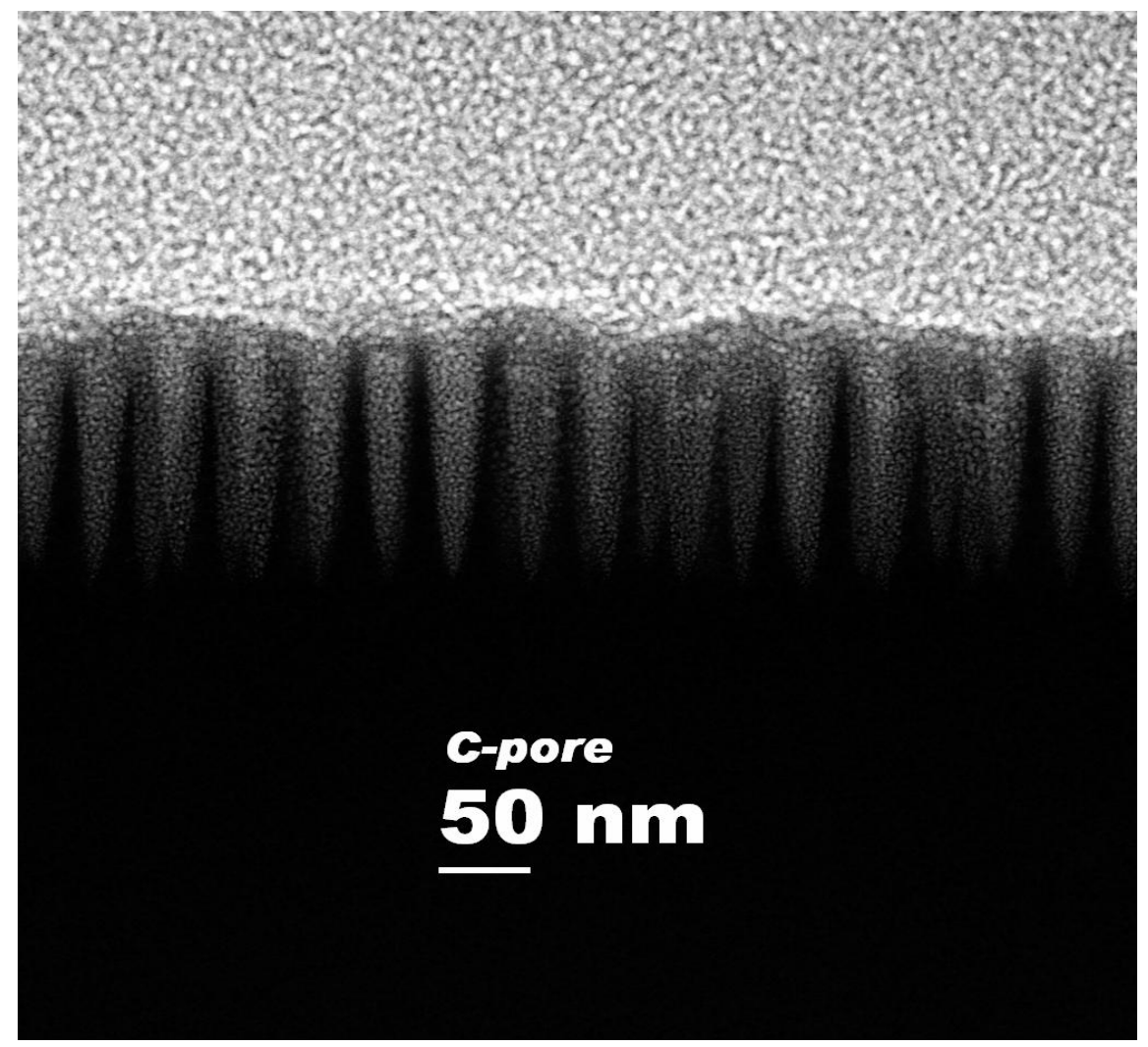

Figure 24. Cross sectional TEM micrograph of pores in etched glassy carbon electrodes.

The surface area of etched glassy carbon was calculated to be significantly higher than that of unetched glassy carbon. The surface area of unetched glassy carbon electrodes exposed during CV measurements was calculated to be $1.69 \mathrm{~cm}^{2}$. The surface area of etched glassy carbon exposed during CV measurements was calculated to be 7.30 $\mathrm{cm}^{2}$. The increase in surface area of etched glassy carbon compared to unetched glassy carbon was approximately $430 \%$. 


\subsection{Electrospun Carbon Fiber Electrodes}

Electrospinning fibers using $1 \mathrm{wt} \%$ co-PAN/DMSO resulted in fibers with diameters in the sub $100 \mathrm{~nm}$ range as shown in Figure 25. Electrospun $1 \mathrm{wt} \%$ coPAN/DMSO fibers were left to dry over night in a hood under air before SEM analysis.

Fiber diameter was measured manually with SEM software. Four sections of electrospun fibers were measured and the average diameter was calculated to be $39 \mathrm{~nm}$ with a standard deviation of $12 \mathrm{~nm}$. Visual inspection of the electrospun fibers show large variances in fiber diameter, ranging from $52 \mathrm{~nm}$ to $23 \mathrm{~nm}$. The wide range of diameters indicated uneven flow of the polymer solution. Whipping of an uneven amount of polymer during electrospinning was the result. If the polymer solution was fed too rapidly, the result would be either a larger diameter fiber or beading on the fiber. The beading would occur if the electric field was not sufficient to whip all of the polymer. To obtain the smallest diameter fibers, polymer exposed to the electric field must be kept to a minimum. To obtain fibers with uniform diameters, a consistent amount of polymer needs to be exposed to the electric field. Any variation to the flow will result in a nonuniform diameter fiber. 


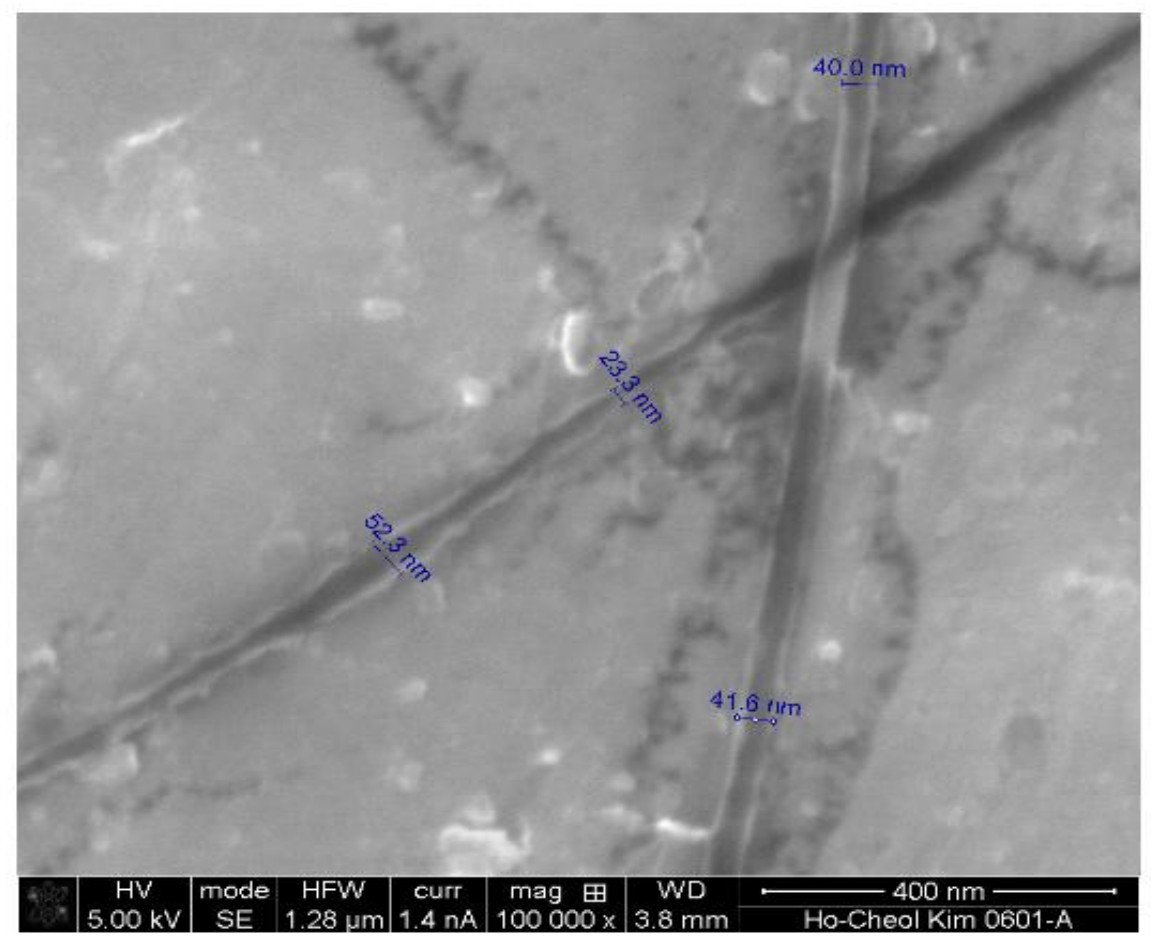

Figure 25. Electrospun polymer fibers on aluminum foil, investigated with SEM.

\subsection{Electrochemical Results of Carbon Electrodes}

Cyclic voltammetry was used to investigate capacitance and electrochemical reactions of glassy carbon, etched glassy carbon, titania-hybridized etched glassy carbon electrodes, and cupric oxide glassy carbon electrodes. The electrochemical setup was discussed in Chapter Four and consisted of the following:

- Electrodes of interest used as the working electrodes (glassy carbon electrodes, etched glassy carbon electrodes, titania-hybridized etched glassy carbon electrodes and cupric oxide-hybridized etched glassy carbon electrodes)

- Platinum counter electrode

- Silver/silver chloride reference electrode

- Electrode holder made of Teflon

- $1 \mathrm{M}$ potassium hydroxide electrolyte

- Potential source 
Cyclic voltammetric results of all electrodes tested experienced higher capacitance during their first cycles of potential. The capacitance region for unetched glassy carbon occurred between $-0.2 \mathrm{~V}$ and $0.4 \mathrm{~V}$. Oxidation and reduction reactions between the electrolyte, carbon, and platinum electrodes occurred outside the potential range. As shown in Figure 26, current density as a function of potential has a slope that was steeper in the positive sweep direction compared to the negative direction. This indicates resistance in the positive sweep direction was higher than in the negative sweep direction. In the positive sweep direction the carbon electrode becomes the anode. As discussed by Morimoto et al., the anode material experiences higher potential than the cathode [21]. Since the current was constant, resistance in the anode must have increased to cause this affect. As more potential sweeps pass through the electrochemical capacitor, resistance and capacitance decreases. This was indicated by decreased areas under the curves and progressively lower resistance. Unetched glassy carbon does not experience any electrochemical reactions with its capacitance region. 


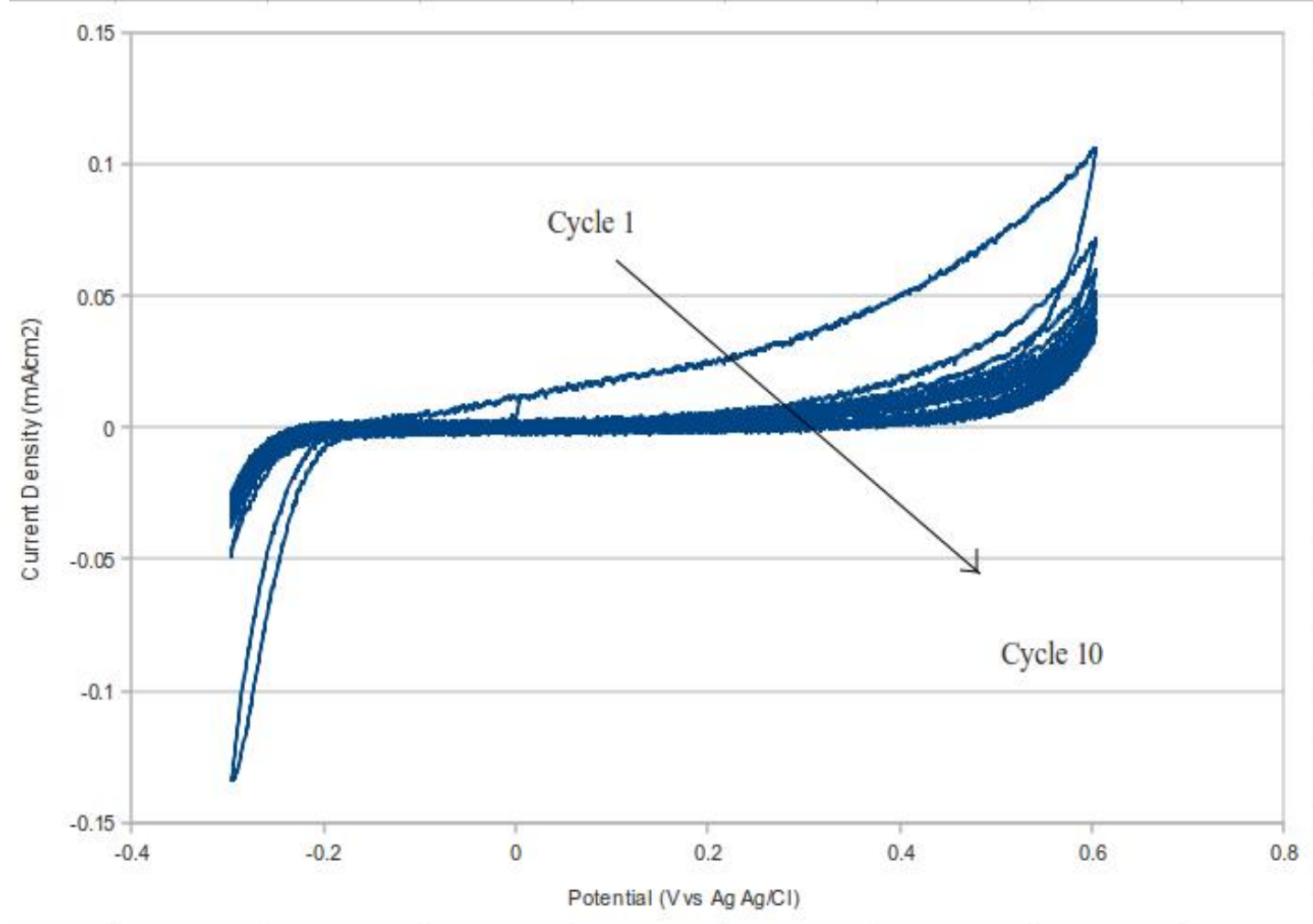

Figure 26. Cyclic voltammetric plot showing 10 cycles of unetched glassy carbon electrodes.

Etched glassy carbon electrodes experience an oxidation peak within its capacitance regions at approximately $0.35 \mathrm{~V}$. An oxidation peak was also observed by Dekanski et al. at approximately $0.25 \mathrm{~V}$ in the negative sweep direction [4]. There was no shift in the oxidation peak over the 10 cycles tested for etched glassy carbon. The capacitance region for etched glassy carbon is located approximately between $-0.2 \mathrm{~V}$ to about $0.4 \mathrm{~V}$. The capacitance and resistivity decrease gradually with subsequent cycling. 


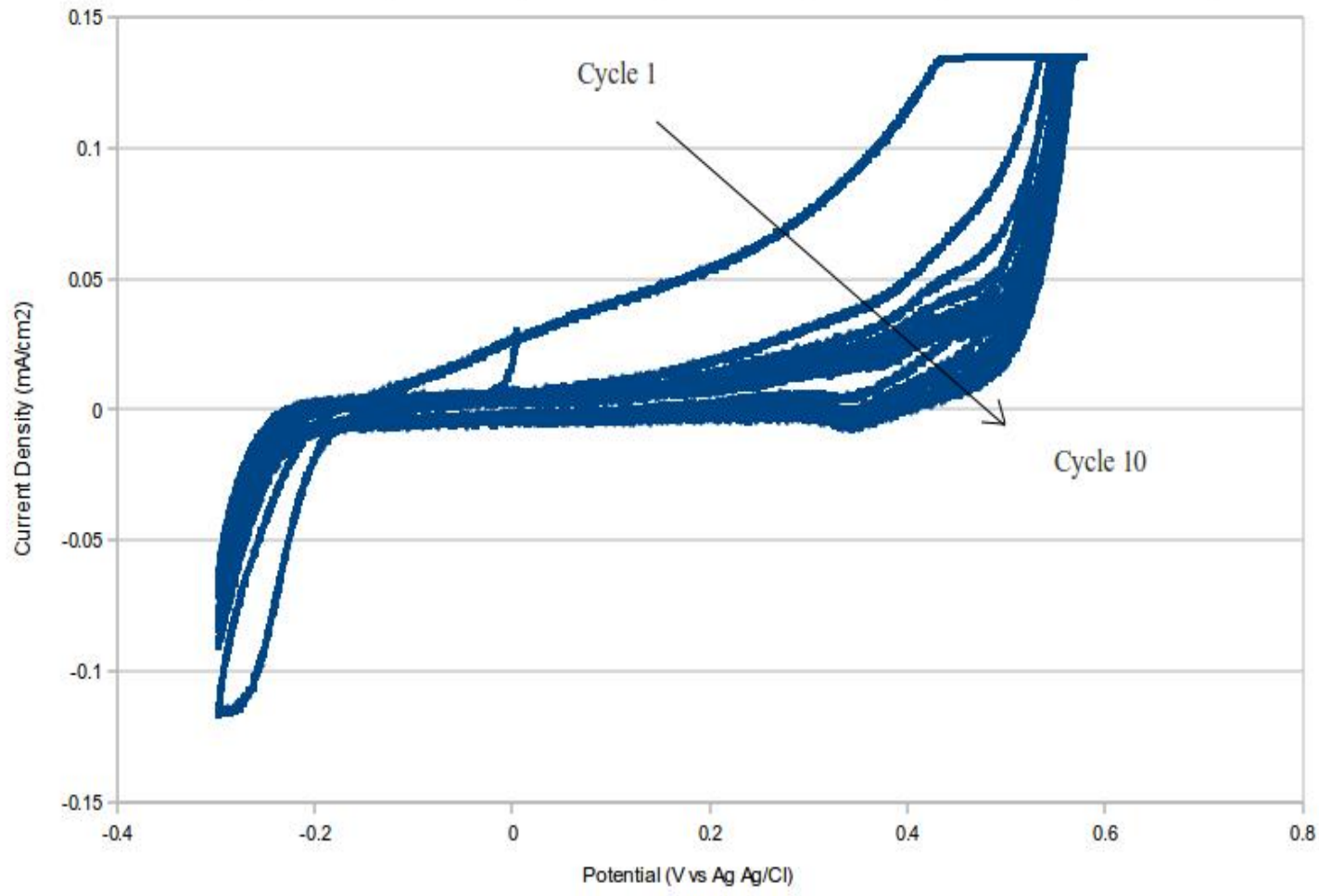

Figure 27. Cyclic voltammetric plot of etched glassy carbon electrodes over 10 cycles.

Capacitance degradation of glassy carbon coated with $\mathrm{TiO}_{2}$ has a similar trend as that of etched glassy carbon. Resistivity does not vary significantly between forward and negative sweep directions during the 10 cycles exposed. This result indicates $\mathrm{TiO}_{2}$ hybridized etched glassy carbon electrodes has better charge/discharge reversibility than etched and unetched glassy carbons. The capacitance region of $\mathrm{TiO}_{2}$-hybridized electrodes occurred between $-0.2 \mathrm{~V}$ and $0.4 \mathrm{~V}$. Titania-hybridized etched glassy carbon electrodes did not experience the same electrochemical reactions in its capacitance region that etched glassy carbon did. 


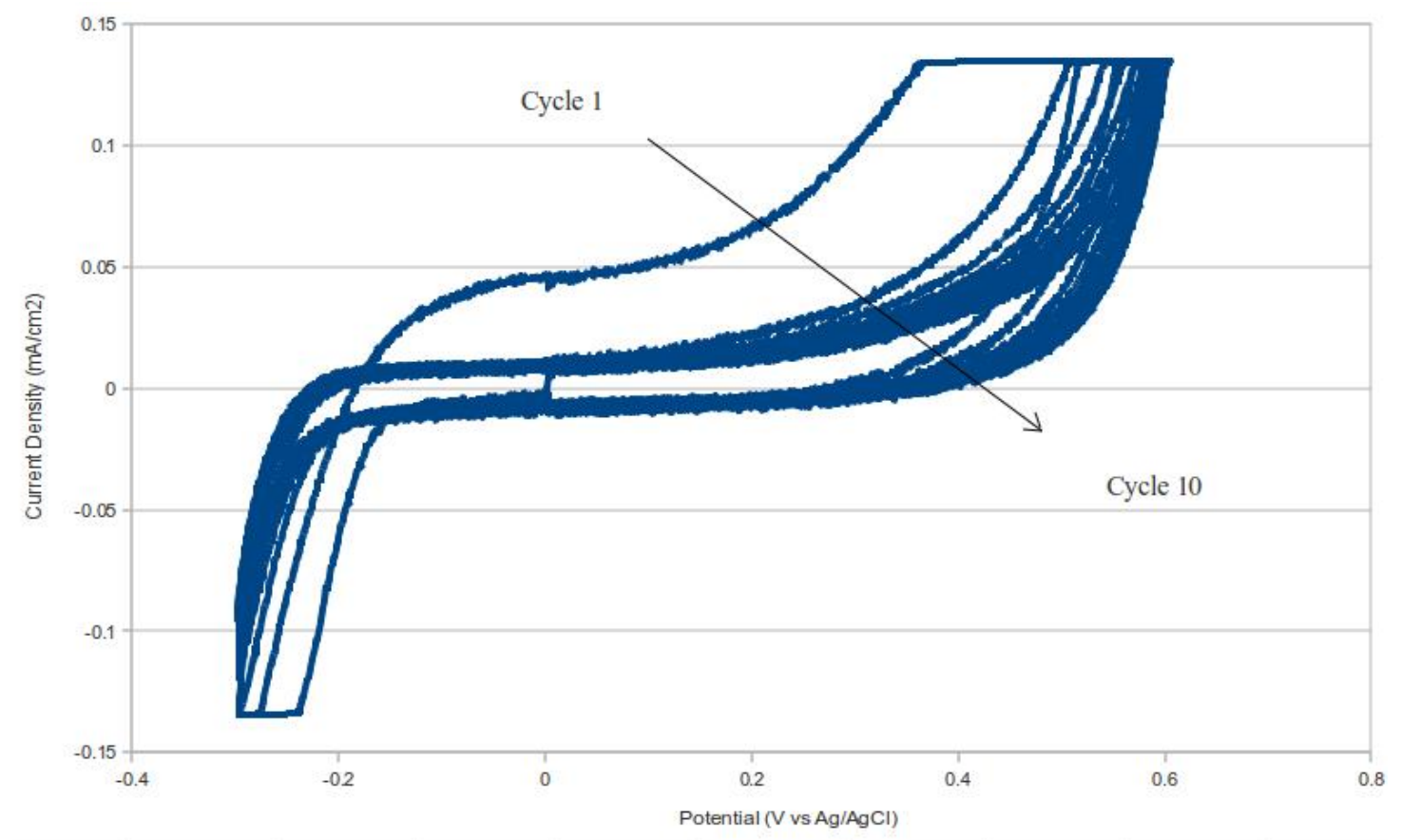

Figure 28. Cyclic voltammetric plot of $\mathrm{TiO}_{2}$-hybridized etched glassy carbon electrodes, showing degradation of capacitance over 10 cycles.

Cupric oxide-hybridized etched glassy carbon electrodes store charge using a combination of capacitance and electrochemical reactions due to the properties of $\mathrm{Cu}_{2} \mathrm{O}$. Oxidation and reduction peaks were observed for $\mathrm{Cu}_{2} \mathrm{O}$-hybridized etched glassy carbon electrodes. As cycling continued, peaks shifted in the positive potential direction. The oxidation peaks were observed at around $0.1 \mathrm{~V}$ in the negative sweep direction. The highest current density magnitude of the oxidation peaks was $-0.25 \mathrm{~mA} / \mathrm{cm}^{2}$. Gradually, the electrochemical peaks shifted towards a potential and current density value of zero. The reduction peaks for $\mathrm{Cu}_{2} \mathrm{O}$-hybridized etched glassy carbon electrodes were observed at around $0.05 \mathrm{~V}$ in the positive sweep direction. The current density of the reduction peaks had values ranging from $0.1 \mathrm{~mA} / \mathrm{cm}^{2}$ to $0.05 \mathrm{~mA} / \mathrm{cm}^{2}$. 


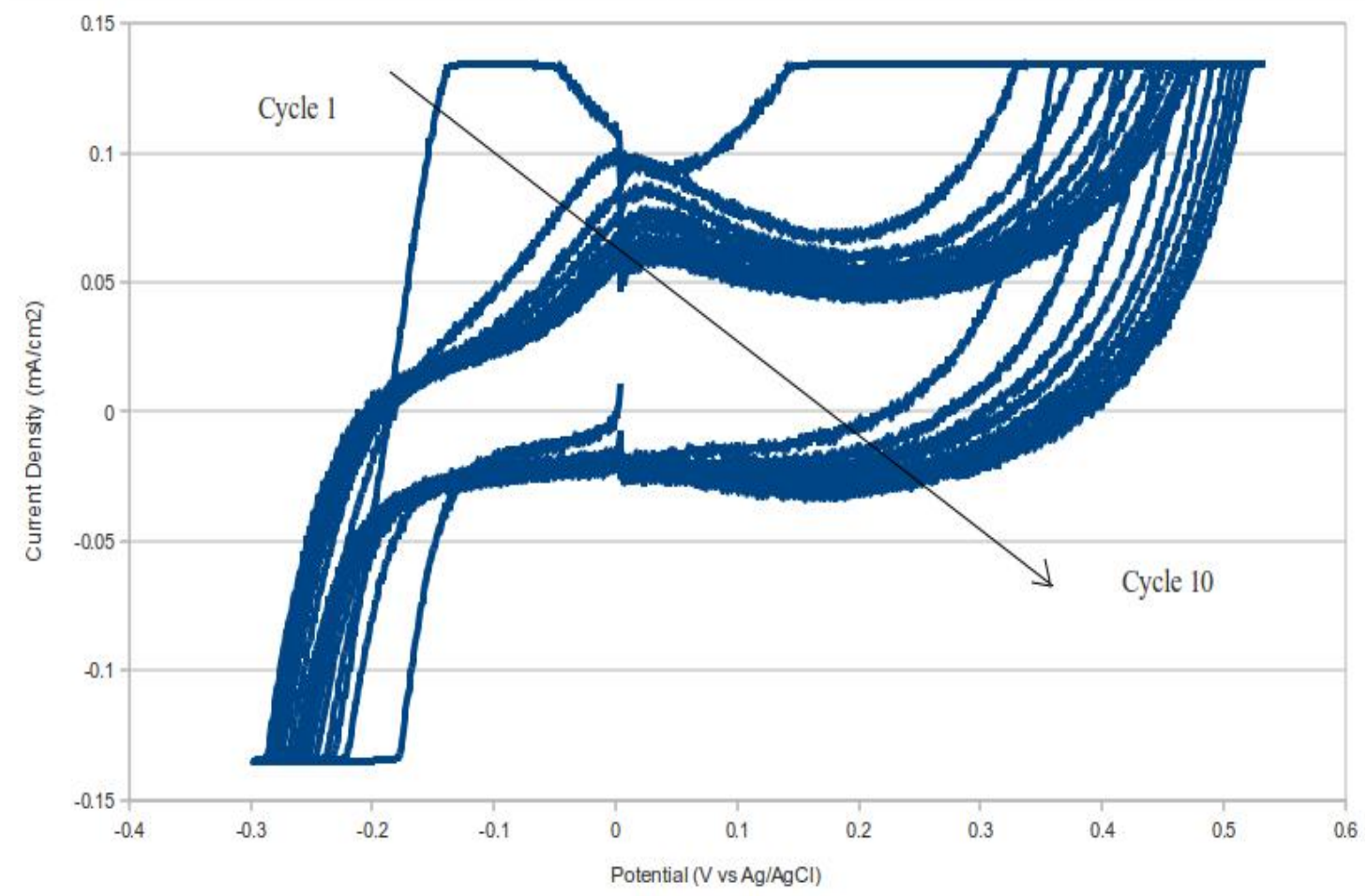

Figure 29. Cyclic voltammetric plot of a $\mathrm{Cu}_{2} \mathrm{O}$-hybridized etched glassy carbon electrode, showing degradation of capacitance over 10 cycles.

Cyclic voltammetric (CV) comparisons between unetched glassy carbon electrodes, etched glassy carbon electrodes, $\mathrm{TiO}_{2}$-hybridized etched glassy carbon electrodes and $\mathrm{Cu}_{2} \mathrm{O}$-hybridized etched glassy carbon electrodes are represented in Figure 30. Each CV loop in Figure 30 was plotted using the second loop for comparison. According to Figure 30, capacitances of the electrodes with surface modification were higher than unetched glassy carbon electrodes. As shown by the larger area under the curves of the surface modified electrode compared to the control electrode capacitance was higher. 


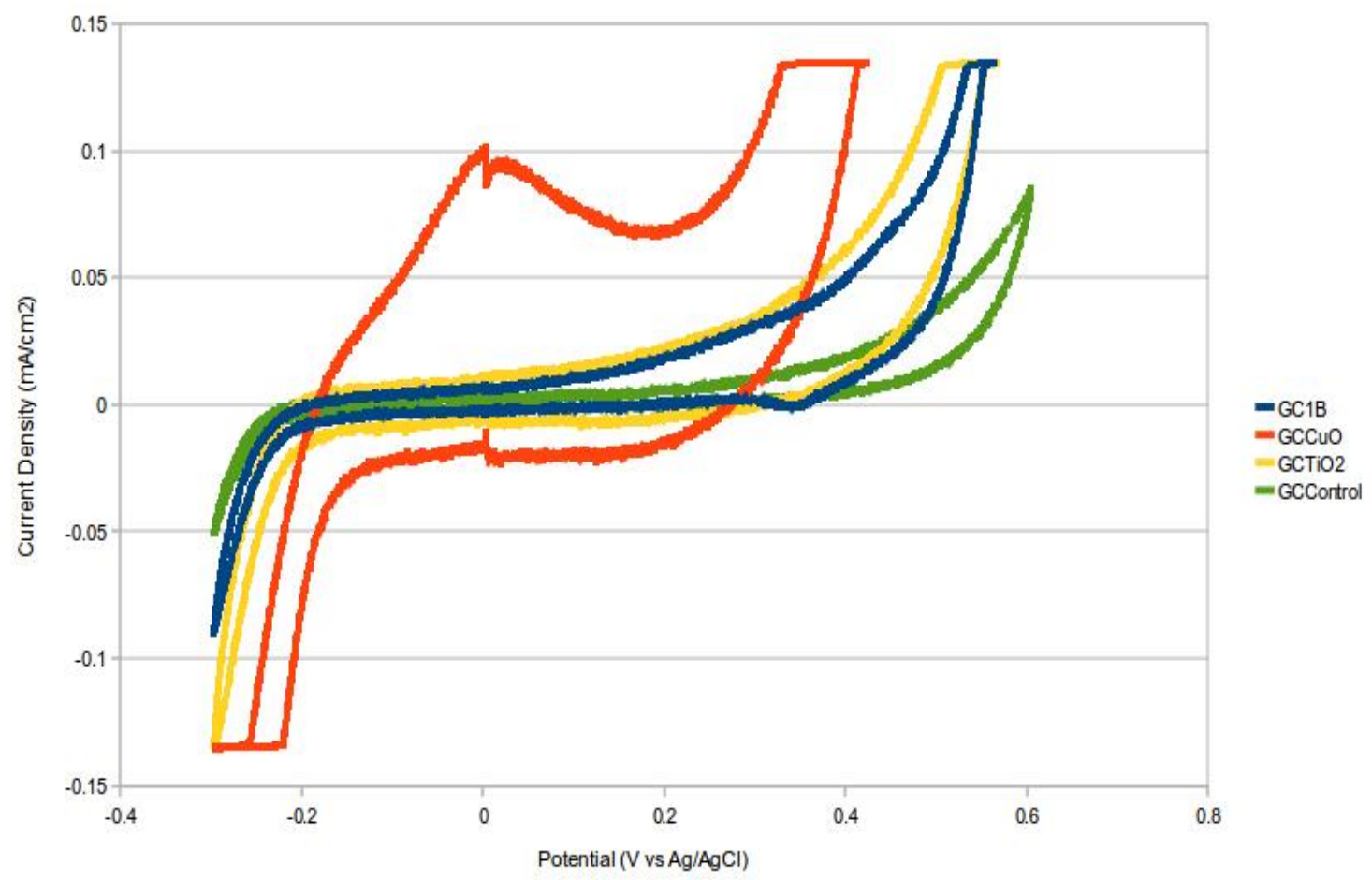

Figure 30. Cyclic voltammetric plots of unetched glassy carbon electrode, etched glassy carbon electrode, $\mathrm{TiO}_{2}$-hybridized etched glassy carbon electrodes, and $\mathrm{Cu}_{2} \mathrm{O}$-hybridized etched glassy carbon.

Capacitances values CV loops represented in Figure 30 are shown in Table 4.

Both etched and $\mathrm{TiO}_{2}$-hybridized etched glassy carbon electrodes have approximately an order of magnitude higher capacitance than unetched glassy carbon. From Table 4, average capacitances of etched and $\mathrm{TiO}_{2}$-hybridized etched glassy carbon electrodes are within an order of magnitude of each other. Capacitance values of $\mathrm{TiO}_{2}$-hybridized etched glassy carbon electrodes versus etched glassy carbon electrodes were almost double. The standard deviations of both etched and $\mathrm{TiO}_{2}$-hybridized etched glassy carbon electrodes are within 1E-05 F of each other. 
Cupric oxide-hybridized etched glassy carbon electrodes have an average capacitance value approximately two orders of magnitude higher than the capacitance of unetched glassy carbon electrodes. The average capacitance calculated for loops 2-10 was $9.67 \mathrm{E}-03 \mathrm{~F}$ with a standard deviation of $1.80 \mathrm{E}-03 \mathrm{~F}$. The average capacitance value of $\mathrm{Cu}_{2} \mathrm{O}$-hybridized etched glassy carbon electrodes is approximately an order of magnitude higher than that of etched and $\mathrm{TiO}_{2}$-hybridized etched glassy carbon electrodes. However, the standard deviation of the capacitance for $\mathrm{Cu}_{2} \mathrm{O}$-hybridized etched glassy carbon electrodes was also an order of magnitude higher than the standard deviations of the capacitances for etched and $\mathrm{TiO}_{2}$-hybridized etched glassy carbon electrodes.

Table 4. Capacitance values for electrodes tested.

\begin{tabular}{|c|c|c|c|}
\hline Electrode Type & $\begin{array}{c}\text { Capacitance of } \\
\text { Second Loop (F) }\end{array}$ & $\begin{array}{c}\text { Average Capacitance } \\
\text { of Cycles 2-10 (F) }\end{array}$ & Standard Deviation \\
\hline $\begin{array}{c}\text { Unetched glassy } \\
\text { carbon }\end{array}$ & $6.70 \mathrm{E}-04$ & $4.38 \mathrm{E}-04$ & $9.95 \mathrm{E}-05$ \\
\hline Etched glassy carbon & $2.19 \mathrm{E}-03$ & $1.31 \mathrm{E}-03$ & $3.97 \mathrm{E}-04$ \\
\hline $\begin{array}{c}\mathrm{TiO}_{2} \text {-hybridized } \\
\text { etched glassy carbon }\end{array}$ & $2.92 \mathrm{E}-03$ & $2.10 \mathrm{E}-03$ & $3.86 \mathrm{E}-04$ \\
\hline $\begin{array}{c}\mathrm{Cu}_{2} \mathrm{O} \text {-hybridized } \\
\text { etched glassy carbon }\end{array}$ & $1.35 \mathrm{E}-02$ & $9.67 \mathrm{E}-03$ & $1.80 \mathrm{E}-03$ \\
\hline
\end{tabular}

Capacitance degrades as cycling continues for electrodes tested, as shown in the plot of capacitance as a function of cycling in Figure 31. The capacitance of $\mathrm{Cu}_{2} \mathrm{O}-$ hybridized etched glassy carbon electrodes remains higher than other electrodes tested for all 10 cycles. However, the reduction in capacitance for $\mathrm{Cu}_{2} \mathrm{O}$-hybridized etched glassy 
carbon electrodes was the highest compared to all other tested electrodes. The degradation of capacitance for $\mathrm{Cu}_{2} \mathrm{O}$-hybridized etched glassy carbon electrodes occurs at a higher rate than the other electrodes tested of 10 cycles. Titania-hybridized etched glassy carbon electrodes retains capacitance higher than etched glassy carbon electrodes over the 10 cycles. Capacitance of unetched glassy carbon electrodes remains the lowest measured capacitance of all electrodes tested over 10 cycles.

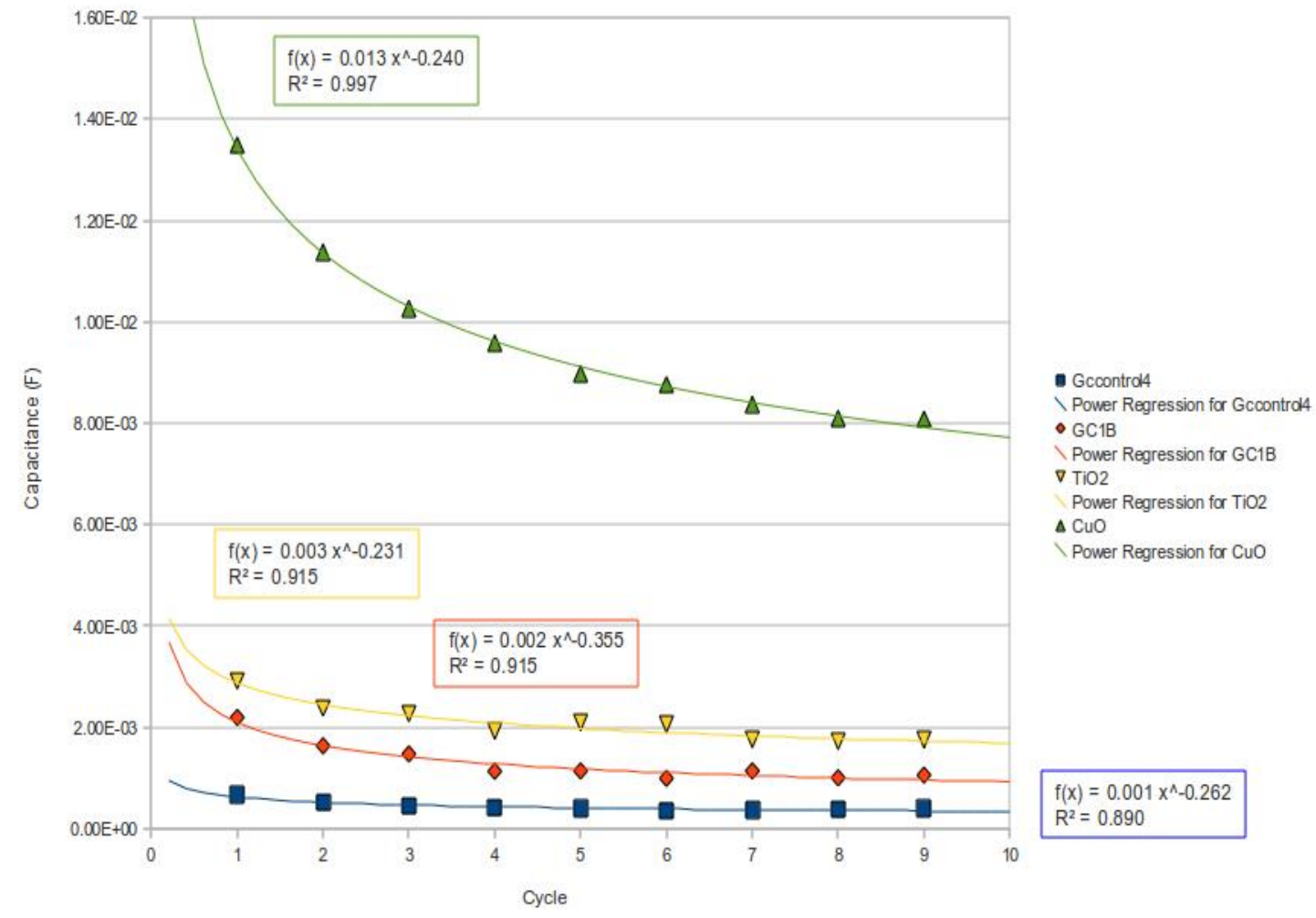

Figure 31. Capacitance as a function of cycling showing power law degradation of electrodes tested.

Capacitance degradation for electrodes tested was fitted with a power law function. Figure 31 indicates the degradation of capacitance may eventually reach a plateau. According to the power law fit of $\mathrm{Cu}_{2} \mathrm{O}$-hybridized etched glassy carbon 
electrodes, capacitance degrades at the highest rate. The degradation of $\mathrm{Cu}_{2} \mathrm{O}$-hybridized etched glassy carbon electrodes was an order of magnitude higher than other electrodes tested. The power law curve fit the degradation of $\mathrm{Cu}_{2} \mathrm{O}$-hybridized etched glassy carbon electrodes with a correlation of $99 \%$. The control glassy carbon electrode experienced the lowest capacitance degradation. However, the power law only had a correlation of $89 \%$ to the degradation data. Etched glassy carbon and $\mathrm{TiO}_{2}$-hybridized electrodes experienced approximately double the amount of degradation experienced by the control glassy carbon. The correlation to the power law of the degradation data for both etched and $\mathrm{TiO}_{2}$-hybridized glassy carbon electrodes was $91 \%$. 


\section{CHAPTER SIX \\ DISCUSSION}

\subsection{Analysis of Physical Characteristics of Etched Glassy Carbon}

The surface area of etched glassy carbon electrodes was calculated using the following steps:

1. manually counting the number of pores in $1 \mathrm{um}^{2}$ area of the SEM image,

2. calculating the number of pores exposed during cyclic voltammetric measurements,

3. subtracting the material removed by etching from the bulk surface area exposed during cyclic voltammetry,

4. adding the surface area of cone pores to the remaining surface area from step three.

Top-down SEM was used to investigate the shapes of pore openings. The pore openings etched into the surface of glassy carbon were determined to be circular. Pore diameters of etched glassy carbon electrodes were measured manually with AFM software. Cone pore profiles in etched glassy carbon were observed using TEM, shown in Figure 24. From Figure 24, pore depth was measured to be approximately $150 \mathrm{~nm}$. Total surface area of etched glassy carbon was calculated using diameters of pores gathered by measurements using AFM software and Figure 24.

Comparing AFM and SEM micrographs of etched glassy carbon electrodes from Figures 22 and 23, respectively, pore-free regions were observed with AFM. However, there were no pore-free regions detected on the surface of etched glassy carbon by SEM. The accuracy of AFM can be affected by particles impeding the tip's ability to interact with surface features. According to the AFM profile of etched glassy carbon, regions containing no pores have amplitudes in the range of $20 \mathrm{~nm}$ higher than edges of the 
pores. According to Kim et al., thickness of the etch mask is approximately $28 \mathrm{~nm}$ [11]. It was possible that some remaining etch mask became attached to and lifted the AFM tip. This may have caused the AFM tip to be raised over the pores to resemble high regions. Another reason for the observation of pore-free regions the environment of AFM measurements. Measurements for AFM were made in atmosphere, where dust may have interacted with the AFM tip to obstruct surface features.

\subsection{Electrochemical Analysis}

Etched glassy carbon electrodes had higher capacitance then glassy carbon electrodes. This was shown by larger current density values in the capacitance regions of cyclic voltammetric plots shown in Figure 27 compared to Figure 26. Titania-hybridized etched glassy carbon electrodes have capacitance values at least an order of magnitude greater than glassy carbon electrodes. This result was due to the increased surface area from etching and the porosity of $\mathrm{TiO}_{2}$. Titania-hybridized etched glassy carbon electrodes have almost double the capacitance of etched glassy carbon electrodes.

The added surface area along with the electrochemical reactions increase the capacitance of $\mathrm{Cu}_{2} \mathrm{O}$-hybridized etched glassy carbon electrodes compared to all electrodes tested. Since electrochemical data of cuprous oxide $(\mathrm{CuO})$ is more readily available than $\mathrm{Cu}_{2} \mathrm{O}, \mathrm{CuO}$ is used to acquire an understanding of $\mathrm{Cu}_{2} \mathrm{O}$ electrochemical characteristics. According to Oral et al., the electrochemical reactions of $\mathrm{CuO}$ come from its p-type conductivity [24]. During potential sweeps, chemical reactions between $\mathrm{Cu}_{2} \mathrm{O}$, potassium hydroxide $(\mathrm{KOH})$, and water creates a flow of ions that cause the electrochemical peaks. 
Cupric oxide-hybridized etched glassy carbon electrodes have capacitance values that are two orders of magnitude higher than the capacitance of glassy carbon electrodes. Cupric oxide-hybridized etched glassy carbon electrodes have capacitance values an order of magnitude higher than etched glassy carbon electrodes and $\mathrm{TiO}_{2}$-hybridized electrodes. However, $\mathrm{Cu}_{2} \mathrm{O}$-hybridized etched glassy carbon electrodes also had a standard deviation that was an order of magnitude higher than the standard deviations of either etched glassy carbon electrodes or $\mathrm{TiO}_{2}$-hybridized etched glassy carbon electrodes. The high standard deviation along with the degradation of capacitance as a function of cycling shown in Figure 31, indicates a rapid degradation in capacitance. Taking the standard deviations into account, the average capacitance of $\mathrm{Cu}_{2} \mathrm{O}$-hybridized etched glassy carbon was only four to seven times higher than etched glassy carbon electrodes and $\mathrm{TiO}_{2}$-hybridized etched glassy carbon electrodes, respectively. Electrochemical peaks were compared to the investigation done by Zhang et al., who investigated gold electrodes coated with $\mathrm{CuO}$ nanobelts [25]. Figure 32 shows the oxidation peaks for $\mathrm{Cu}_{2} \mathrm{O}$ around $-0.1 \mathrm{~V}$ as tested by Zhang et al. The magnitudes of the oxidation peaks obtained from Zhang et al. were higher than those obtained by $\mathrm{Cu}_{2} \mathrm{O}$ hybridized etched glassy carbon electrodes. Probable reasons for the variation was the electrolyte and the reference electrode used. Electrolyte and reference electrode used by Zhang et al. was $0.1 \mathrm{M}$ phosphate and saturated calomel, respectively [25]. These two variables affect the potentials and magnitudes of the electrochemical peaks. However, the results obtained by Zhang et al. resemble results obtained from cyclic voltammetric measurements of $\mathrm{Cu}_{2} \mathrm{O}$-hybridized etched glassy carbon electrodes. 


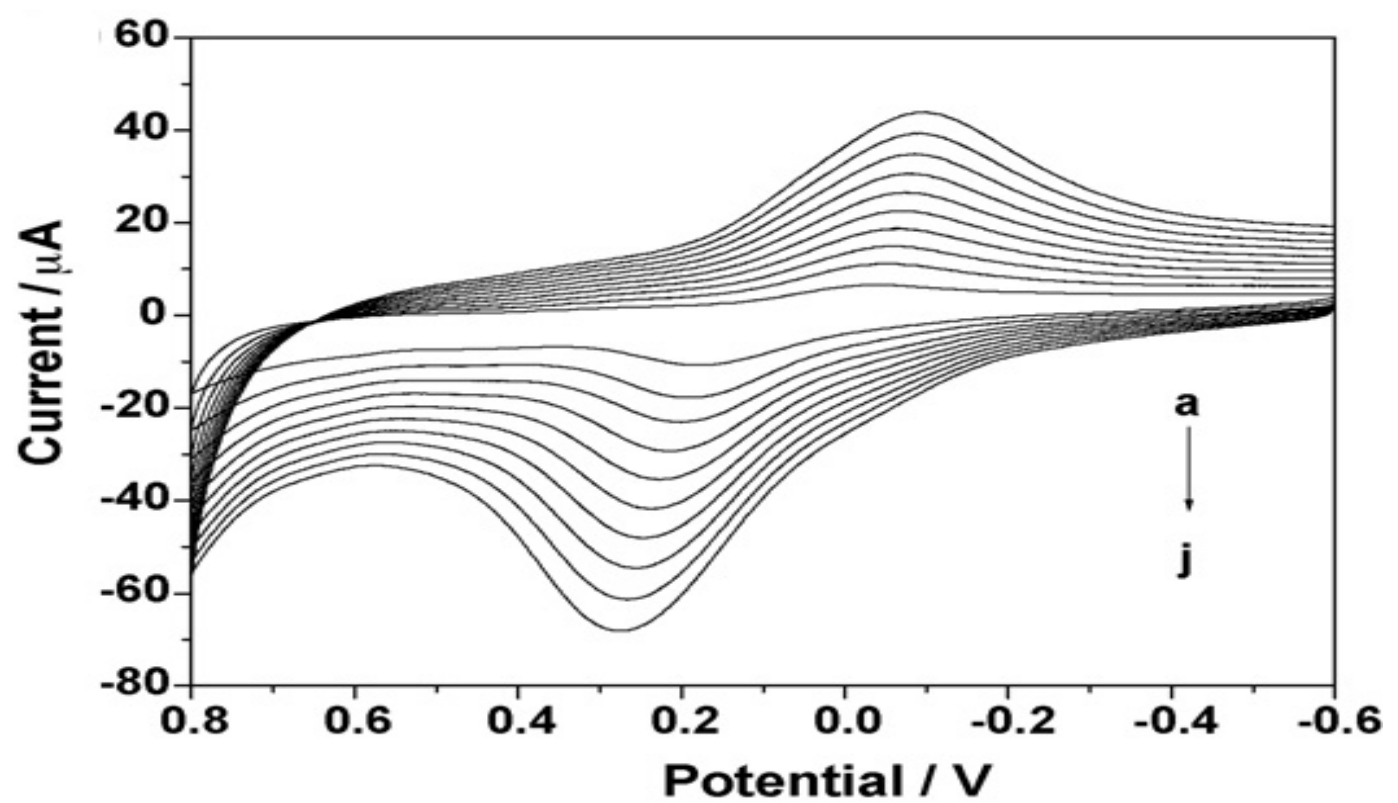

Figure 32. Cyclic voltammetric plot of a gold electrode coated with $\mathrm{CuO}$ nanobelts (Reprinted with permission from X. Zhang, G. Wang, Q. Wang, L. Zhao, M. Wang and B. Fang, Copyright 2009, Mater. Sci. Eng. B.)

The rapid rate of capacitance degradation gradually decreases as cycling continued. This was due to ions occupying surface area, which decreases accessibility of surface area in later cycles. Ions moving into free surface area are not obstructed by ions during the initial sweeps. After every switch in sweep direction, more ions become stuck to the surface, which reduces availability of free surface for ions to attach. Reduced capacitance was the result of a lower surface area accessible to ions. Capacitance degradation appears to plateau after about 10 cycles. This may be due to reaching an equilibrium between ions stuck to the surface and leaving the surface of the electrodes.

Etched glassy carbon experiences oxidation reaction at approximately $0.3 \mathrm{~V}$ in the negative sweep direction only as shown in Figure 27. A possible cause was the added surface energy caused by etching. As discussed in Chapter Two by Frankowiak and 
Beguin, carbon does experience electrochemical reactions, that are dependent on surface modifications [5]. Glassy carbon has fewer broken bonds than etched glassy carbon due to the lack of surface roughness. The added broken bonds, increases surface energy and the reactiveness of etched glassy carbon.

\subsection{Physical Characteristics Analysis of Electrospun Fibers}

Non-uniform diameters of electrospun polymer fibers were a result of a parameter or combination of parameters not being optimized. Regions with larger diameters can be reduced by increasing both the potential and working distance to allow the fiber more time and energy to whip the fiber. Decreasing viscosity of the polymer solution may work as well. However, if viscosity was too low, polymer solution will spray instead of forming fibers. 


\section{CHAPTER SEVEN \\ CONCLUSION}

The study showed surface modification of glassy carbon electrodes increased charge storage capacities. Preamble experiments were performed to determine fabrication and experimental parameters of the etch mask and electrospun fibers. Block copolymers with pore diameters of $20 \mathrm{~nm}$ were used to test the effectiveness of using etch masks to form ordered pores on glassy carbon electrodes. Coated glassy carbon electrodes were etched to produce ordered cone-shaped pores under the surface. As a result, surface area was increased by approximately $430 \%$ compared to unetched glassy carbon electrodes. Etched glassy carbon electrodes were hybridized with $\mathrm{TiO}_{2}$ and $\mathrm{Cu}_{2} \mathrm{O}$ to enhance charge-storage properties. Surface etching and hybridization improved capacitance of carbon electrode material by increasing surface area and introducing electrochemical reactions. Cyclic voltammetric measurements showed an increased capacitance for modified carbon electrodes. Figure 31 shows capacitance degradation as a function of cycling continues for each of the electrodes tested. The capacitance degradation of etched, unetched and $\mathrm{TiO}_{2}$-hybridized glassy carbon electrodes was lower than the degradation of capacitance for $\mathrm{Cu}_{2} \mathrm{O}$-hybridized etched glassy carbon electrodes. This was due to the ability of ions to cycle between $\mathrm{Cu}_{2} \mathrm{O}, \mathrm{KOH}$, and water in the potential range tested. Electrospun fibers were fabricated with diameters under $50 \mathrm{~nm}$. However, no electrochemical experiments were conducted on these electrospun fibers. 


\section{CHAPTER EIGHT \\ FUTURE WORK}

Electrospun polymer fibers were fabricated and carbonized, but not electrochemically investigated. Issues rose due to the extremely brittle nature of carbonized fibers. Parameters for polymer solutions need to be investigated to improve the mechanical properties of the final carbon material. Examples of these parameters are: polymer molecular weights, concentration of polymer solutions, and solvents used in polymer solutions. Polymer solutions and electrospinning parameters need to be examined for porous and hollow fibers. Polymer solutions mixed with carbon nanoparticles can also be experimented with to avoid carbonization. Avoiding carbonization may allow for a tougher final material than carbonized electrospun fibers. Electrochemical investigations need to be performed to determine the capacitance of these high surface area electrodes. 


\section{REFERENCES}

1. J.B. Goodenough, H.D. Abruna and M.V. Buchanan (2007). Basic Research Needs For Electrical Energy Storage [Online]. Available at http://www.sc.doe.gov/bes/reports/files/EES_rpt.pdf (accessed 9 November 2009). Posted pdf file.

2. M. Winter and R.J. Brodd, "What Are Batteries, Fuel Cells, and Supercapacitors?," Chem. Rev., 104, 4245-4269 (2004).

3. W.G. Pell and B.E. Conway, "Peculiarities and Requirements of Asymmetric Capacitor Devices Based on Combination of Capacitor and Battery-Type Electrodes," J. Power Sources, 136, 334-345 (2004).

4. A. Dekanski, J. Stevanovic, R. Stevanovic, B.Z. Nikolic and V.M. Jovanovic, "Glassy Carbon Electrodes I. Characterization and Electrochemical Activation," Carbon, 39, 1195-1205 (2001).

5. E. Frankowiak and F. Beguin, "Carbon Materials for Electrochemical Storage of Energy in Capacitors," Carbon, 39, 937-950 (2001).

6. J. Chmiola, G. Yushin, Y. Gogotsi, C. Portet, P, Simon and P.L. Taberna, "Anomalous Increase in Carbon Capacitance at Pore Sizes Less than 1 Nanometer," Science, 313, 1703-1760 (2006).

7. H. Malmberg, M. Zuleta, A. Lundblad and P. Bjornbom, "Ionic Transport in Pores in Activated Carbon for EDLCs,'J. Electrochem. Soc., 153(10), A1914A1921 (2006).

8. J. Huang, B.J. Sumpter and V. Meunier, "Theoretical Model of Nanoporous Carbon Supercapacitors,” Angew. Chem. Int. Ed., 47, 520-524 (2008).

9. C. Largeot, C. Portet, J. Chmiola, P.L. Taberna, Y. Gogotsi, P. Simon, "Relation Between Ion Size and Pore Size for Electric-Double-Layer Capacitor,' J. Am. Chem. Soc., 130, 2730-2731 (2008).

10. H.C. Kim, S.M. Park and W.D. Hinsberg, "Block Copolymer Based Nanostructures: Materials, Processes, and Applications to Electronics," Chem. Rev., 110, 146-177, (2009).

11. S. Kim, R.M. Briber, A. Karim, R.L. Jones and H.C. Kim, "EnvironmentControlled Spin Coating To Rapidly Orient Microdomains in Thin Block Copolymer Films," Macromolecules, 40, $4102-4105$ (2007). 
12. H.C. Kim and W.D. Hinsberg, "Surface Patterns From Block Copolymer SelfAssembly," J. Vac. Sci. Technol. A, 26(6), 1369-1382 (2008).

13. D. Li and Y. Xia, "Electrospinning of Nanofibers: Reinventing the Wheel?," Adv. Mater., 16(14), 1151-1171 (2004).

14. E. Zussman, A.L. Yarin, A.V. Bazilevsky, R. Avrahami and M. Feldman, "Electrospun Polyacrylonitrile/Poly(Methyl Methacrylate)-Derived Turbostatic Carbon Micro-/Nanotubes," Adv. Mater., 18, 348-353 (2006).

15. S.V. Fridrikh, J.H. Yu, M.P. Brenner and G.C. Rutledge, "Controlling the Fiber Diameter During Electrospinning,” Phys. Rev. Lett., 90(14), (2003).

16. D.H. Reneker and A.L. Yarin, "Electrospinning Jets and Polymer Nanofibers," Polymer, 49, 2387-2425 (2008).

17. Y. Wen, G. Cao and Y. Yang, "Studies of Nanoporous Glassy Carbon as a New Electrochemical Capacitor Material," J. Power Sources, 148, 121-128 (2005).

18. L. Ji, Y. Yao, O. Toprakci, Z. Lin, Y. Liang, Q. Shi, A.J. Medford, C.R. Millns and X. Zhang, "Fabrication of Carbon Nanofiber-Driven Electrodes from Electrospun Polyacrylonitrile/Polyprrole Bicomponents for High-Performance Rechargeable Lithium-Ion Batteries," J. Power Sources, 1-7 (2009).

19. C.A. Frysz, X. Shui and D.D.L. Chung, "Electrochemical Behavior of Porous Carbons," Carbon, 35(7), 893-916 (1997).

20. D.W. Wang, F. Li and H.M. Cheng, "Hierarchical Porous Nickel Oxide and Carbon as Electrode Materials for Asymmetric Supercapacitor," J. Power Sources, 185, 1563-1568, (2008).

21. T. Morimoto, K. Hiratsuka, Y. Sanada and K. Kurihara, "Electric Double-Layer Capacitor Using Organic Electrolyte,” J. Power Sources, 60, 239-247 (1996).

22. S. Prabaharan, R. Vimala and Z. Zainal, "Nanostructured Mesoporous Carbon as Electrodes for Supercapacitors,” J. Power Sources, 161, 730-736 (2006).

23. M. Watt-Smith, S. Rigby, T. Ralph and F. Walsh, "Characterization of Porous Carbon Electrode Materials used in Proton Exchange Membrane Fuel Cells via Gas Adsorption," J. Power Sources, 184, 29-37 (2008). 
24. A.Y. Oral, E. Mensur, M.H. Aslan and E. Basaran, "The Preparation of Copper(II) Oxide Thin Films and the Study of their Microstructures and Optical Properties," Mater. Chem. Phys., 83, 140-144 (2004).

25. X. Zhang, G. Wang, Q. Wang, L. Zhao, M. Wang and B. Fang, "Cupreous Oxide Nanobelts as Detector for Determination of L-Tyrosine," Mater. Sci. Eng. B, 156, 6-9 (2009). 